\title{
Improved Configurations For Liquefied Natural Gas Cycles
}

\author{
Said Al Rabadi ${ }^{1 *}$, Rainer Sapper ${ }^{2}$, Sadeq Emeish ${ }^{3}$, Falah Banihani ${ }^{4}$ \\ 1) Al-Balqa Applied University, Department of Chemical Engineering, , 19117 Salt, Jordan, \\ 2) Technical Manager, The Linde Group, Dr.-Carl-von-Linde-Strase 6-14, 82049 Pullach im Isartal/ Germany \\ 3) Department of Chemical Engineering, Al-Balqa Applied University, 19117 Salt, Jordan \\ 4) Department of Chemical Engineering, Al-Balqa Applied University, 19117 Salt, Jordan
}

\begin{abstract}
The most important challenge in a natural gas liquefaction plant is to improve the plant energy efficiency. A process topology should be implemented, which results in a considerable reduction of energy consumption as the natural gas liquefaction process consumes a large amount of energy. In particular, system design focusing on configuring cold part cycle is an attractive option. In this study, various energy recovery-oriented process configurations and the potential improvements of energy savings for small- \& midscale liquefied natural gas plants were proposed and compared with almost exclusively commercial trademarks processes. These improved simulation based investigations were validated under the variation in feed gas pressure, mixed refrigerant cooling reference temperature and the pinch temperature of cryogenic plate fin heat exchanger. The simulation results exhibited considerable reduction of specific total energy consumption. Therefore, the proposed liquefaction cycles have a simple topology, hence lower capital cost and compacter plant layout, which is compatible for power-efficient, offshore, floating liquefied natural gas liquefaction plants.
\end{abstract}

Keywords: Liquefaction, natural gas, mixed refrigerant cycle, power-efficient, design criteria

\section{Introduction}

Liquefaction process of natural gas includes the physical conversion of NG from gas to liquid phase. Liquefied natural gas takes up a factor of about 1/600th the volume of natural gas in the gaseous state. The natural gas is then condensed into a liquid phase at close to atmospheric pressure by cooling it to approximately $-160^{\circ} \mathrm{C}\left(-260^{\circ} \mathrm{F}\right)$ (Smith et al . (1996), Cengel and Boles (2002), Jacobson (2009)). Cryogenic LNG carriers or cryogenic road/trail tankers are used for its transport. LNG is principally used for transporting natural gas, where it is then re-gasified and distributed to the markets.

The natural gas fed into the LNG plant will be treated to remove condensate, Mercury, $\mathrm{H}_{2} \mathrm{~S}$, COx and NOx that will freeze under the cryogenic temperature ranges (Devold (2013), Metz and Davidson (2005)). A typical LNG process is shown in Figure 1. NG is first extracted and transported to a processing plant, where the feed gas pressure is presumed at a certain value. After that NG is treated against any heavy hydrocarbons and mud/ slug, it is then purified by removing acid gases such as $\mathrm{CO}_{2}, \mathrm{NOx}$ and $\mathrm{H}_{2} \mathrm{~S}$ by utilizing an Amine washing solvent. This solvent is regenerated by introducing it to stripper column (by products like sour gas and waste water are obtained and disregarded to a battery limit). At this stage the sweet NG stream is wet and still might contain traces of Mercury, LNG process train is designed to remove any $\mathrm{Hg}$ content to prevent mercury amalgamizing with aluminium in the cryogenic heat exchangers, while the water content is adsorbed in a special dehydration unit. The drier is regenerated by the boil off gas obtained from downstream LNG storage unit. The gas is then cooled down in stages until it is liquefied. LNG is finally stored in storage tanks to be loaded and shipped. The heart of a LNG plant, as highlighted in Fig. 1, is NG liquefaction and refrigeration cycle, where these stages are the highest energy density units of a LNG plant. Hence then designing these units will have the major impact on the capital and operating costs of the plant. In order to reach the cryogenic temperature ranges for liquefying NG, a mixture of Nitrogen and light hydrocarbons mainly Methane, Ethane and Propane is implemented as refrigerant.

As shown in PT curve for different gases, presented in Figure 2, where the vapour pressure is plotted as a function of gas temperature. Such a refrigerant mixture can reduce the process temperature to a cryogenic range lower than $-190^{\circ} \mathrm{C}$ at $1 \mathrm{bar}$, which is quite enough for liquefying NG. The composition of MRC is subject to alternation depending on the NG composition as well to the feed gas operating pressure (shown in the variation of NG condensation curves at pressure of 1 bar and 25 bar) and the reference cooling refrigeration temperature

Received on June 4, 2018; accepted on 20 August, 2018, Correspondence concerning this article should be addressed to Said Al Rabadi (e-mail address: said.alrabadi@bau.edu.jo). ORCiD ID of Said Al Rabadi https https://orcid.org/0000-0002-6007-2853 


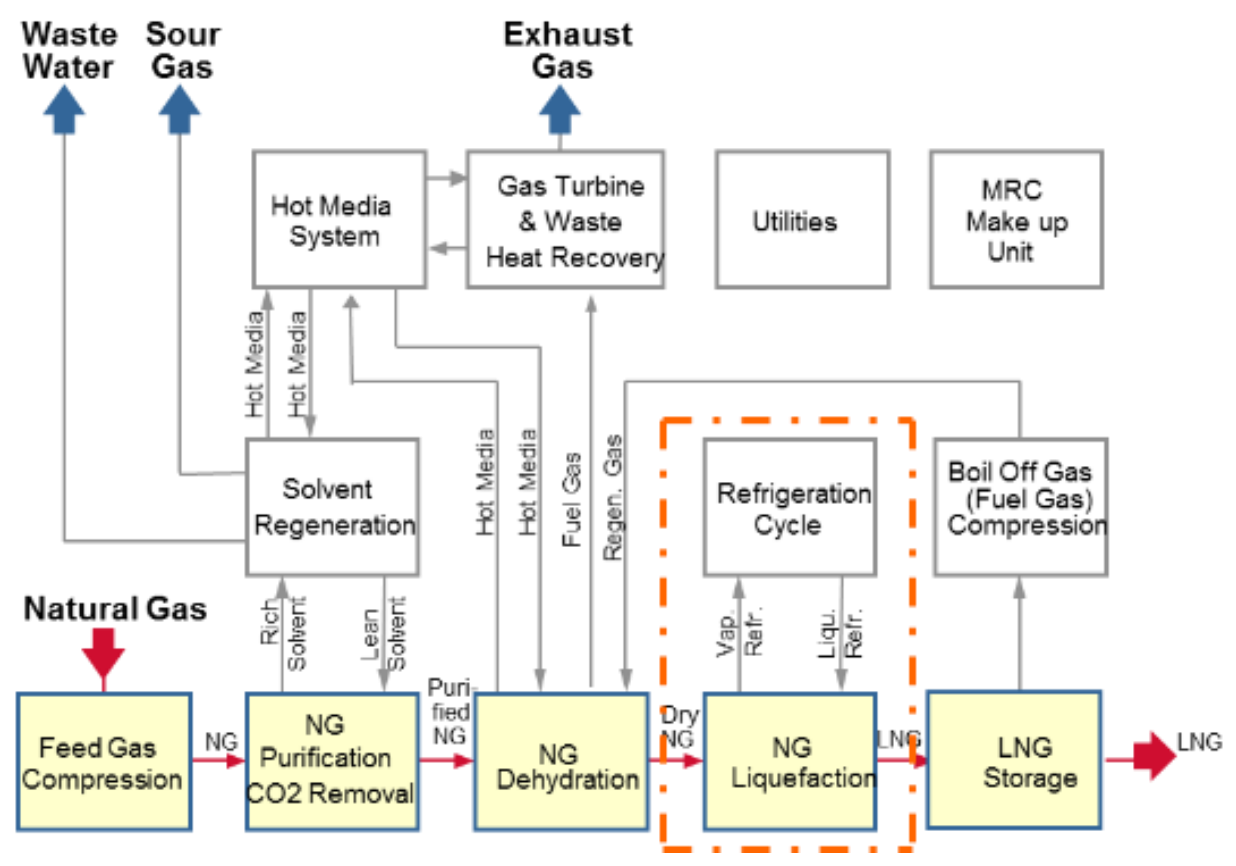

Fig. 1 Block diagram of a LNG process, (Devold (2013))

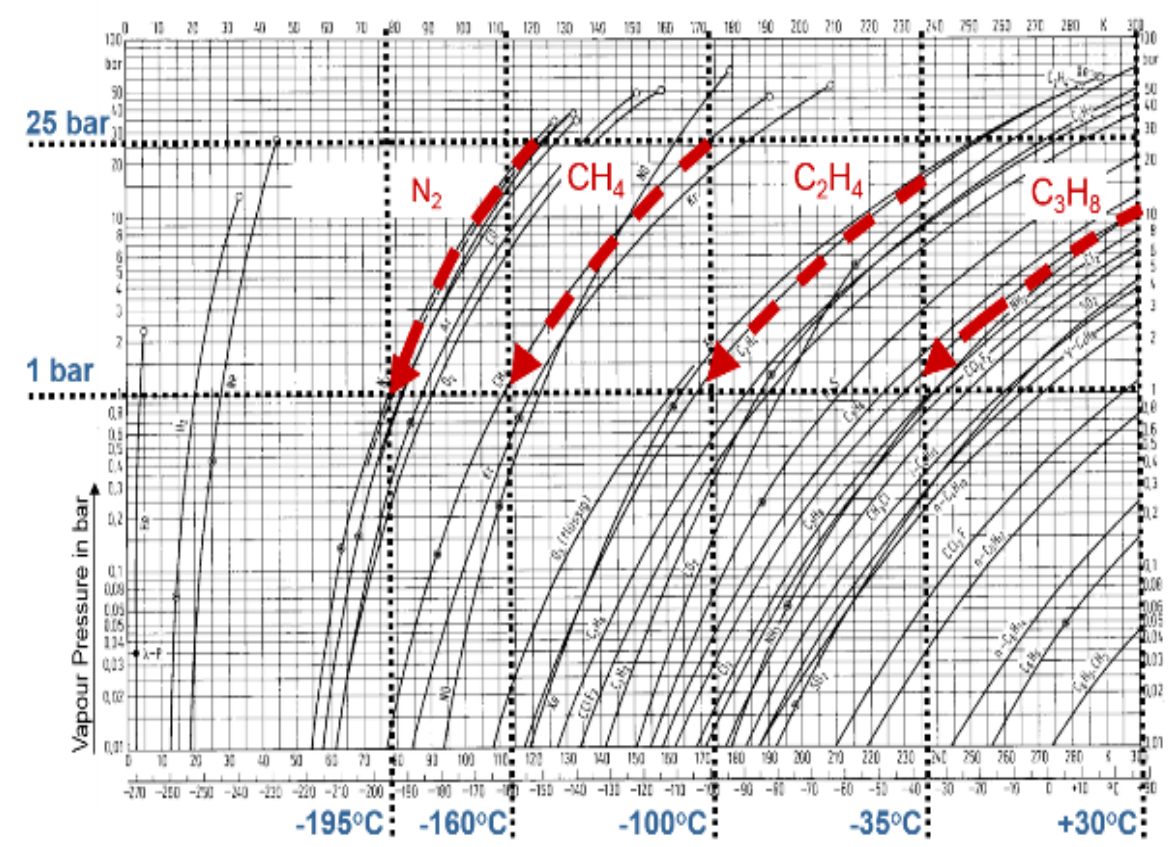

Fig. 2 PT diagram from different gases (Smith et al. (1996))

LNG processes are licensed by large oil and gas companies, but are generally based on a one- or multi-stage cooling process with pure or mixed refrigerants (Long et al. (2016)). The main types of LNG process are listed in Table 1, including mainly cascade, MR and expander/ booster processes. Each process has different characteristics in scalability, investment cost and energy efficiency. For floating LNG, e.g., possibly lower weight is desired due to its low CAPEX, even its energy efficiency is significantly lower than the best cascade or MR processes. The reason is that the gas has a heat load to temperature $(\mathrm{Q} / \mathrm{T})$ curve that will improve stability, throughput and efficiency. The curve tends to show three distinct regions; pre-cooling, liquefaction and sub-cooling. All of these regions are 
characterized by having different curve behaviours, or specific heats, along the process. Keep in mind that the (Q/T) curve shape is different for different gas compositions.

Table 1 List of commercial LNG refrigeration processes

\begin{tabular}{|c|c|c|c|}
\hline \multicolumn{2}{|r|}{ Process } & Licenser & Features \\
\hline \multirow{4}{*}{$\sum_{n=1}^{\mathfrak{n}}$} & $\begin{array}{l}\text { PRI CO } \\
\text { [Andress (1996)] }\end{array}$ & Black \& Veatch & SMR, Limited capacity $\leq 1.3$ MTPA, low CAPEX \\
\hline & $\begin{array}{l}\text { DMR } \\
\text { [Agrawal (1998)] }\end{array}$ & Shell & Two refrigerant cycles, large scale, high CAPEX \\
\hline & $\begin{array}{l}\text { MFCP } \\
\text { [Foss (2005), Coll (2008), } \\
\text { Wonsub and Kwangho } \\
(2013)]\end{array}$ & Statoil/ Linde & $\begin{array}{l}\text { Mixed refrigerant cycles, large capacity, need for external refrigerants } \\
\text { storage, high CAPEX }\end{array}$ \\
\hline & $\begin{array}{l}\text { LIMUM [Stockman et al. } \\
(2002)]\end{array}$ & Linde & SMR, large scale, need for external refrigerants storage \\
\hline \multirow{3}{*}{ 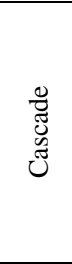 } & $\begin{array}{l}\text { Cascade cycle } \\
\text { [Pereira and Lequisiga } \\
(2014), \text { Andress (1996)] }\end{array}$ & Conoco Phillips & $\begin{array}{l}\text { Separate refrigerant cycles with C1, Ethylene and C3, large capacity, } \\
\text { high CAPEX }\end{array}$ \\
\hline & $\begin{array}{l}\text { C3MR } \\
\text { [Pereira and Lequisiga } \\
(2014)]\end{array}$ & APCI & $\begin{array}{l}\text { Utilizes two C } 3 \text { and MR cycles, widely spread, large capacity } \geq 5 \\
\text { MTPA, low energy density }\end{array}$ \\
\hline & $\begin{array}{l}\text { Self-refrigerated LNG } \\
\text { [Fischer-Calderon (2003)] }\end{array}$ & BP & $\begin{array}{l}\text { No compressor, low production rate (high energy density), capacities } \geq \\
1.3 \text { MTPA }\end{array}$ \\
\hline 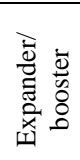 & $\begin{array}{l}\text { Expander cycle } \\
{[\text { Perez and Dietz (2009), }} \\
\text { Wonsub and Kwangho } \\
(2013)]]\end{array}$ & Kryopak & Expander/ booster, no liquid refrigerant, high energy density \\
\hline
\end{tabular}

\section{Materials and Methods}

In this study, simulation based investigations on the NG liquefaction and refrigeration cycle with different topologies were performed, utilizing the so called OPTISIM ${ }^{\circledR}$ as the process simulator, which is still under development and is thus not fully adopting actual mainstream strategies in process industry. Nevertheless, OPTISIM proves its strength in process design and rating as well as in process dynamic simulations. An outline of the simulator's key features is presented in (Kroner (2006)).

Also these investigations are valid for small- \& mid-scale plants from the plant capacity point of view. The purpose of these theoretical investigations is to identify the improvements of process configurations of natural gas liquefaction cycles, and to be compared with trademarks of refrigeration processes. The comparing criteria include the specific energy consumption with respect to the variation in feed gas pressure, MR cooling reference temperature and the pinch temperature of PFHE. impacts on the design criteria of PFHE, named as NG stream to PFHE, LNG product stream from PFHE routed to LNG storage tank and Fuel stream obtained as boil off gas stream from storage tank. The Fuel stream is principally a cold temperature stream that should be warmed to near room temperature conditions for better combustion conditions as well to get benefit of its cooling duty in PFHE, hence to decrease cooling duty of MRC compressor.

The pre-defined process parameters are listed in Table 2. Three main streams are foreseen that have the major impacts on the design criteria of PFHE, named as NG stream to PFHE, LNG product stream from PFHE routed to LNG storage tank and Fuel stream obtained as boil off gas stream from storage tank. The Fuel stream is principally a cold temperature stream that should be warmed to near room temperature conditions for better combustion conditions as well to get benefit of its cooling duty in PFHE, hence to decrease cooling duty of MRC compressor. A typical lean natural gas feed stream is considered for the theoretical investigations, where its Methane content concentrates to more than $90 \mathrm{~mol} \%$ due to upstream processing units (namely Slug Catcher for capturing solid particulates in NG feed, Amine washing and dehydration (Jacobson (2009), Devold (2013), Metz and Davidson (2005), Laursen and Karavanov (2006)) of other associated components in NG. Ethane and Propane contents in LNG stream are presumed around the typical figures in order to meet the foreseen heating value of LNG; typical LNG heating values in the range of 41,000 - 50,000 kJ/kg (Foss, 2005). Nitrogen due to its lower boiling temperature than that of Methane basically concentrates in the fuel gas stream, which can be operated by conventional gas turbine without further obstacles (Coll et al. (2008)) 
Table 2 Process parameters of natural gas streams

\begin{tabular}{|l|l|l|l|l|}
\hline Stream & NG & LNG & Fuel \\
\hline Temp. & {$[\mathrm{K}]$} & 303.2 & 112.0 & 299.0 \\
\hline P & {$[\mathrm{bar}]$} & 65 & 1.2 & 1 \\
\hline Mass flow & {$[\mathrm{t} / \mathrm{h}]$} & 339.7 & 300 & 39.7 \\
\hline CH4 & {$[\mathrm{mol} \mathrm{\% ]}$} & 91.7 & 92.9 & 81.98 \\
\hline C2H6 & {$[\mathrm{mol} \%]$} & 5.25 & 5.9 & 0.01 \\
\hline C3H8 & {$[\mathrm{mol} \mathrm{\% ]}$} & 0.35 & 0.4 & trace \\
\hline N2 & {$[\mathrm{mol} \%]$} & 2.7 & 0.8 & 18.01 \\
\hline
\end{tabular}

Table 3 Overview of MRC boundary conditions for all investigated processes valid for a MR cooling reference temperature of $30^{\circ} \mathrm{C}$ and an outlet pressure of 65 bar from MRC 2nd stage cycle compressor

\begin{tabular}{|c|c|c|c|c|c|c|c|}
\hline \multirow[b]{2}{*}{ Process } & \multicolumn{7}{|c|}{ MRC process conditions (These figures are deduced from reference operating plant) } \\
\hline & 1 & 2 & 3 & 4 & 5 & 6 & 7 \\
\hline \multicolumn{8}{|l|}{ PFHE } \\
\hline $\mathrm{dT}_{\min }[\mathrm{K}]$ & 2.0 & 3.7 & 3.7 & 3.8 & 3.6 & 3.6 & 3.6 \\
\hline $\mathrm{d}_{\mathrm{pFuel}}[\mathrm{bar}]$ & 0.2 & 0.2 & 0.2 & 0.2 & 0.2 & 0.2 & 0.2 \\
\hline $\mathrm{d}_{\mathrm{p}}[\mathrm{bar}]$ & 0.4 & 0.4 & 0.4 & 0.4 & 0.4 & 0.4 & 0.4 \\
\hline $\mathrm{Q}_{\text {iso }}[\mathrm{kWh} / \mathrm{tLNG}]$ & 3.33 & 3.33 & 3.33 & 3.33 & 3.33 & 3.33 & 3.33 \\
\hline \multicolumn{8}{|c|}{ MRC $1^{\text {st }}$ Stage Compressor } \\
\hline$\eta_{\text {isen }}[\%]$ & 80 & 80 & 80 & 80 & 80 & 80 & 80 \\
\hline $\mathrm{T}_{\text {inlet }}[\mathrm{K}]$ & 299.9 & 298.2 & 298.6 & 300.5 & 299.5 & 300.6 & 298.9 \\
\hline $\mathrm{T}_{\text {outlet }}[\mathrm{K}]$ & 376.9 & 409.6 & 383.5 & 389.6 & 376.3 & 373.4 & 385.2 \\
\hline Poutlet [bar] & 26.2 & 39.0 & 25.9 & 17.3 & 24.8 & 25.8 & 26.1 \\
\hline $\mathrm{d}_{\mathrm{p}}[\mathrm{bar}]$ & 0.3 & 0.3 & 0.3 & 0.3 & 0.3 & 0.3 & 0.3 \\
\hline \multicolumn{8}{|c|}{ MRC $2^{\text {nd }}$ Stage Compressor } \\
\hline$\eta_{\text {isen }}[\%]$ & 80 & 80 & 80 & 80 & 80 & 80 & 80 \\
\hline $\mathrm{T}_{\text {outlet }}[\mathrm{K}]$ & 423.1 & 339.4 & 369.0 & 393.7 & 380.6 & 370.5 & 395.6 \\
\hline $\mathrm{P}_{\text {outlet }}[\mathrm{bar}]$ & 65 & 65 & 65 & 65 & 65 & 65 & 65 \\
\hline \multicolumn{8}{|l|}{ MRC $_{\text {pump }}$} \\
\hline$P_{\text {inlet }}[\mathrm{bar}]$ & - & - & 25.4 & 16.8 & 24.3 & 25.3 & - \\
\hline \multicolumn{8}{|c|}{ Cooling Water Heat Exchangers } \\
\hline $\mathrm{dp}_{\mathrm{MR}}[\mathrm{bar}]$ & 0.5 & 0.5 & 0.5 & 0.5 & 0.5 & 0.5 & 0.5 \\
\hline
\end{tabular}

Table 3 shows the boundary conditions for all MRC processes. These boundary conditions are valid for a MR cooling reference temperature of $30^{\circ} \mathrm{C}$ and an outlet pressure of 65 bar from $2^{\text {nd }}$ stage cycle compressor. Based on practice of the MRC processes for small- \& mid-scale plants with different configurations, seven topologies are presented below for the purpose of these investigations. They utilize SMR liquefaction process with two stages MRC compressors. In the first stage the pressure is increased from suction pressure of about 2 bar to MP figures, and in the second stage the MP values are increased to HP of 65 bars. This value is kept identical and is set as simulation constraint for all investigated processes. Process 1 and 7 represent the so called PRICO and the enhanced PRICO processes respectively (Andress (1996)), while 2 till 5 actual topologies collected from built small- \& mid-scale LNG plants (Foss (2005), Coll (2008), Wonsub and Kwangho (2013)), which were constructed and taken in operation under different metrological regions. Process 6 is enriched with potential modifications with the aim to increase the refrigeration process efficiency as well as plant stability (Al Rabadi (2017)). Followingly, a brief description of each process is presented.

In principle, process 1 (Andress (1996)), is a MRC process without MRC pump non MP separator, Fig. 3. The cooling is provided by a closed MRC, which consists of components mixture like Nitrogen, Methane, Ethane and Propane, its composition depends on the process operating conditions. The refrigerant is withdrawn from PFHE at a temperature of approx. 299.9K and a pressure of about 2 bar. It is compressed in the 1st stage refrigerant cycle compressor, and cooled against cooling water in Cycle Compressor After cooler to a MR cooling reference temperature of $30^{\circ} \mathrm{C}$. 


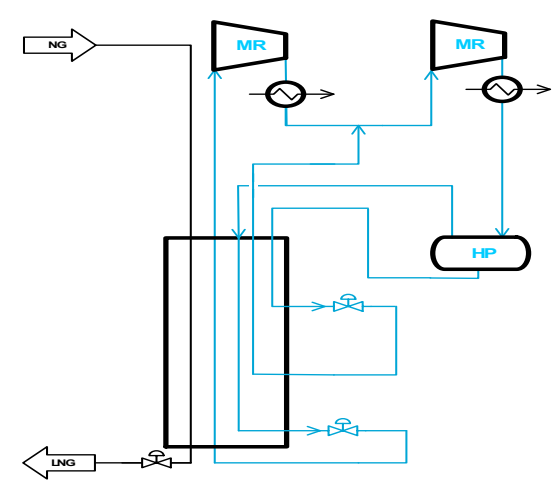

Fig. 3 Descriptive sketch of process 1 (Andress (1996))

The gaseous refrigerant is further compressed in the $2^{\text {nd }}$ stage cycle compressor and afterwards cooled against cooling water to a MR cooling reference temperature of $30^{\circ} \mathrm{C}$. The gas will be partially condensed. Liquid and gas are separated in HP Separator. The liquid from the HP separator is rooted to PFHE where it is sub-cooled and then is used for the pre-cooling of the natural gas after expansion in a Joule-Thomson expansion valve. The gas MR from HP separator is cooled in PFHE and provides the final coldness for the natural gas sub-cooling after expansion in Joule-Thomson expansion valve. After expansion to a pressure of approx. 2.6 bar, the gas MR stream is warmed up in PFHE and returns to the suction side of the 1st stage Cycle Compressor. The composition of the MRC stream to the 2nd stage cycle compressor is changed due to mixing the liquid MR stream routed from HP separator to PFHE with the outlet stream from $1^{\text {st }}$ stage after cooler. The cycle liquid refrigerant stream routed from HP separator to PFHE is overheated above dew point temperature with a temperature safety margin of $5 \mathrm{~K}$ for protecting the downstream MRC compressor from two-phase flow. Make up for the refrigerant system is required mainly due to MR losses via the gas seals of the MRC Compressor.

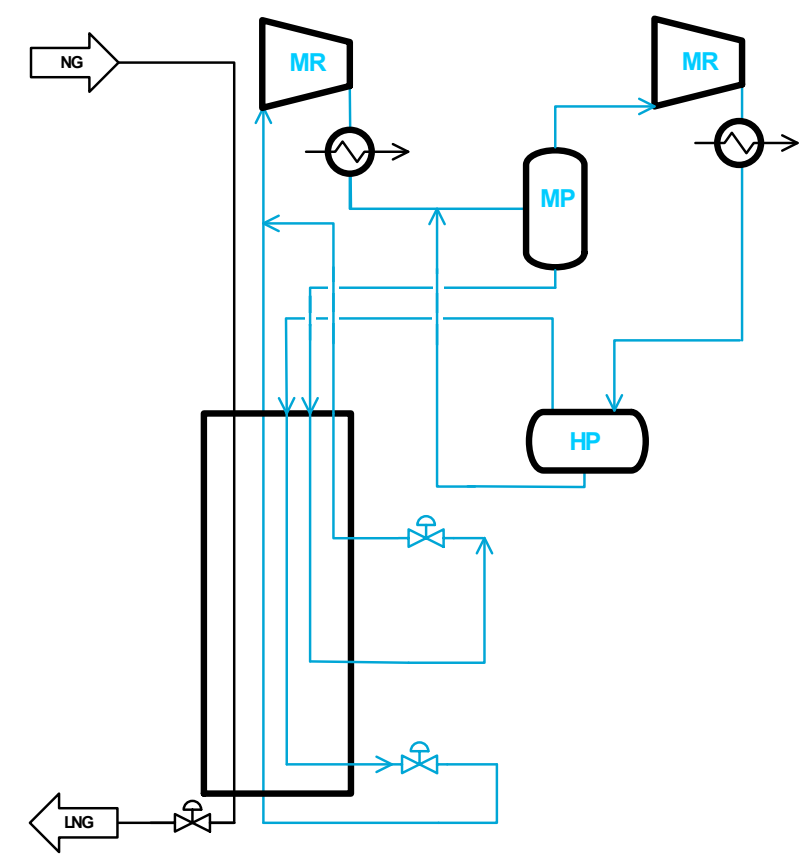

Fig. 4 Descriptive sketch of Process 2 (Foss (2005))

Process 2: MRC Process (Foss, 2005) is without MRC pump identical to process 1, nevertheless with inclusion of MP separator, refer to Figure 4, other process flow conditions are almost similar. MP separator is foreseen to have an impact on the behaviour of (Q/T) diagram in the pre-cooling region, through the inclusion of liquid MP MR to PFHE and hence changing the NG pre-cooling duty. HP MR liquid stream provides the pre-cooling duty of NG after expansion in JT valve provides the sub-cooling duty of NG at the warm end of PFHE. While HP MR gas stream provides the sub-cooling at the cold end of PFHE after expansion in JT valve. 
Process 3: Coll (2008) presents this MRC process with MP separator like in process 2, with the difference of liquid MR from MP separator is pumped and combined with the partially condensed outlet MR stream from MRC 2nd stage compressor after cooler, then it is routed to HP separator. Although of the expected higher energy consumption due to MRC pump as well increased CAPEX, Proces s 3 is modified to meet certain cooling process demands, refer to Figure $\mathbf{5}$.

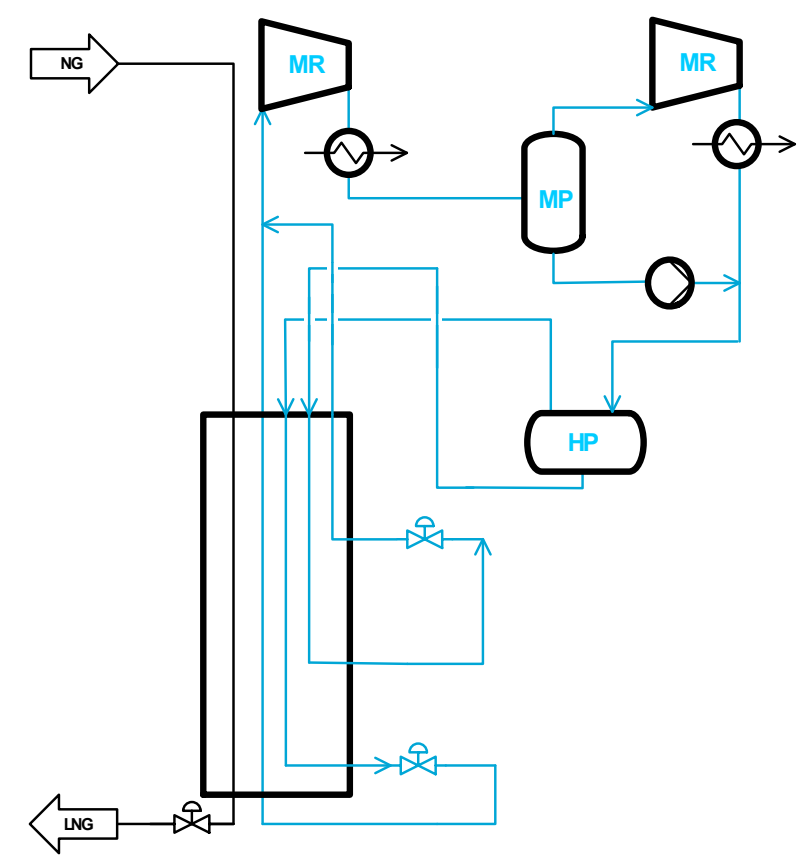

Fig. 5 Descriptive sketch of Process 3 (Coll (2008))

Process 4: is given in (Wonsub and Kwangho (2013)) as a MRC Process with mixing liquid and gaseous MR streams from both warm \& cold ends of PFHE, refer to Figure 6, other MRC process conditions are identical to process 3. The MR gas stream from HP separator is combined with the MR liquid stream (mixing cold and warm parts of PFHE), then both streams are joined and warmed up in PFHE and return to the suction side of the 1st stage Cycle Compressor. Although keeping this stream at a safety margin from dew point to protect the downstream 1st stage MRC compressor, the combination of both streams have to a great extent an impact on liquefaction duty of PFHE.

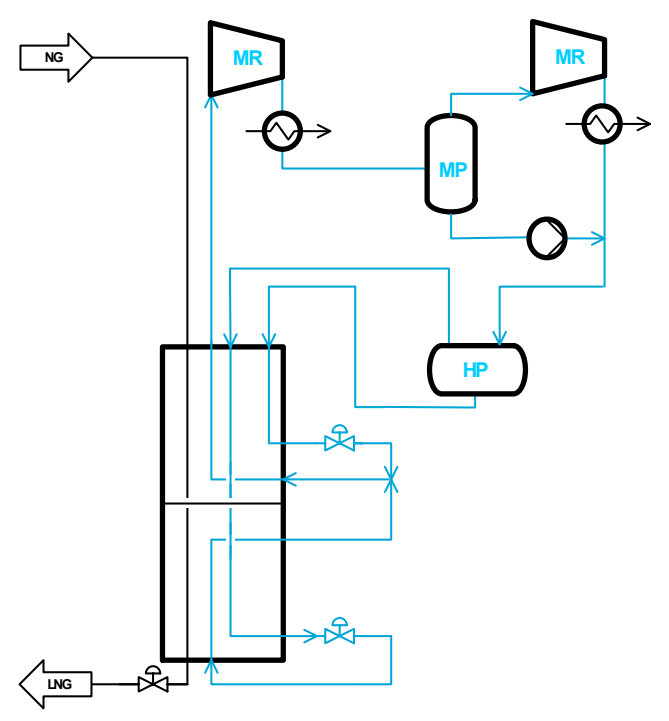

Fig. 6 Descriptive sketch of Process 4 (Wonsub and Kwangho (2013)) 
Process 5: Refrigeration Process with mixing liquid and gas HP MR streams from both warm \& cold ends of PFHE, and using a cold MRC separator at the cold end of PFHE (Wonsub and Kwangho (2013)), other MRC process conditions are identical to process 4, refer to Figure 7. The liquid from the cold MRC separator is sub-cooled in PFHE and is used as refrigerant for PFHE after expansion in a Joule Thomson expansion valve. The gas stream from the cold MRC separator is cooled, hence is partially condensed in PFHE to provide the final coldness for NG sub-cooling after expansion in a JT val.ve. Then the HP MR gas stream is warmed up in PFHE and mixed with the cycle MR liquid stream from the cold MRC separator after expansion at the cold part of PFHE, then the resulting two phase stream is warmed up in PFHE. The two phase stream is mixed again with the cycle liquid MR stream after expansion at the warm part of PFHE then returns to the suction side of the 1st stage Cycle Compressor. In spite of the increased CAPEX of this process, it is believed that the combined two phase MR stream would provide more significant pre-cooling duty of PFHE, as well achieved a considerable safety margin from dew point of this stream to protect 1st Stage MRC compressor.

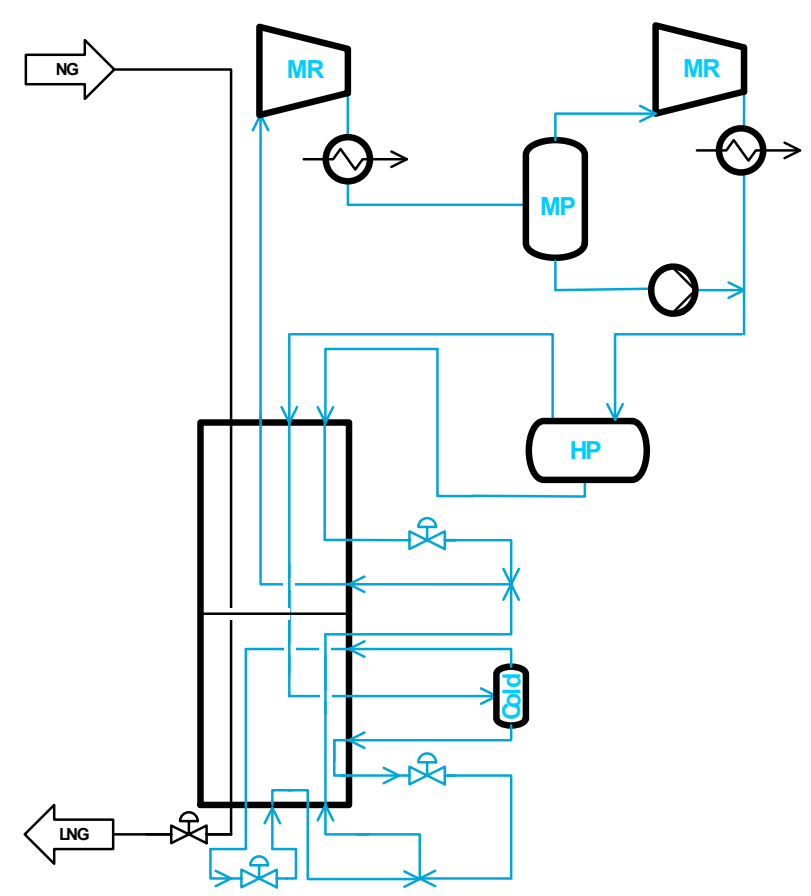

Fig. 7 Descriptive sketch of Process 5 (Wonsub and Kwangho (2013))

Process 6: MRC Process with PFHE, is considered for the comparison in these investigations and is briefly presented in (Al Rabadi (2017)). New process improvements are introduced to its topology with respect to what was given in (Stockman et al. (2002)); two MRC pumps are implemented in this process. First to pump liquid MR stream from MP separator to HP separator, the second pump is used to transport liquid MR from HP separator to be combined with the gaseous MR from HP separator. Combined stream, after expansion in JT valve, it provides the liquefaction and pre-cooling duties of PFHE, refer to Figure 8 . It is believed, of the increased number of pumps, that the PFHE is compared to process 5. Hence then a significant lower layout of the cold box is achieved. 


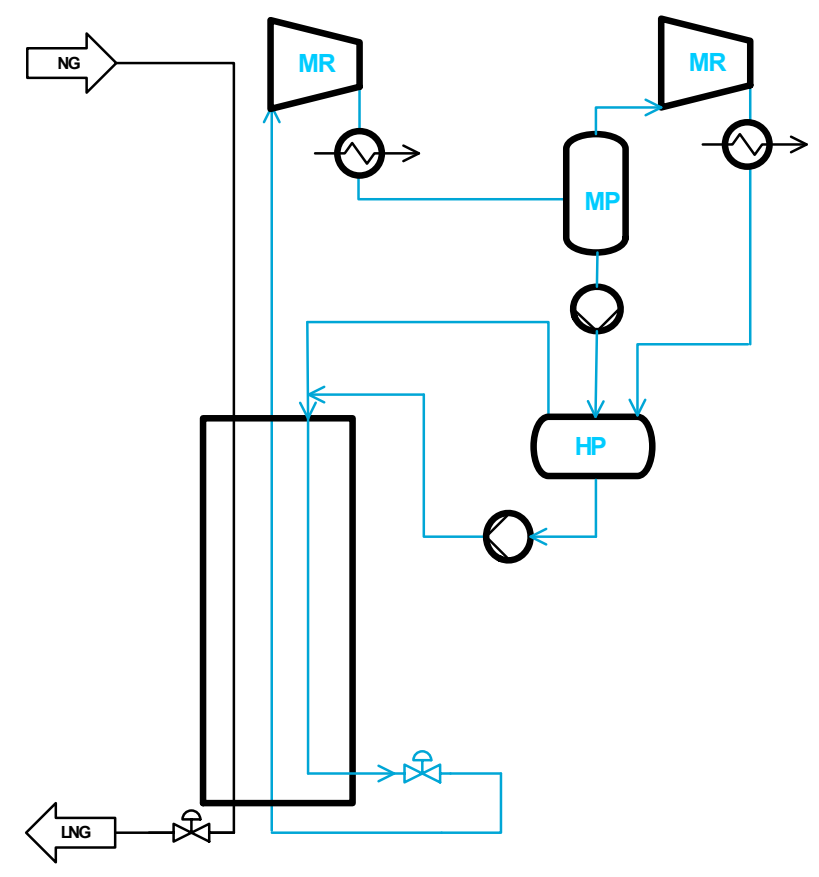

Fig. 8 Descriptive sketch of Process 6 (Model Refrigeration concept)

Process 7: so called Enhanced PRICO process is presented in (Andress (1996)) and is illustrated in Figure 9. Briefly, this MRC process topology is almost similar to that of process 5, with the difference that liquid MR from HP separator is routed back after expansion in JT valve to a traditional shell and tube heat exchanger, where it is warmed against the liquid MR from MP separator to essentially provide the pre-cooling duty of PFHE through the liquid MR from MP separator after its JT expansion at the warm end of PFHE. As mentioned above, the presence of cold MR separator promotes the sub-cooling duty of PFHE.

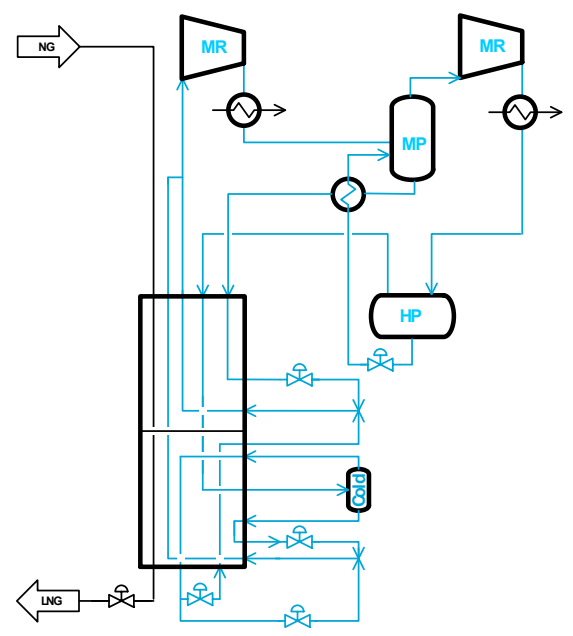

Fig. 9 Descriptive sketch of Process 7 (Andress (1996))

\section{Results and Discussion}

The findings of the theoretical investigations of the above mentioned processes are outlined through the behavior of $(\mathrm{Q} / \mathrm{T})$ diagram of PFHE for each process, and specific total energy consumption (energy consumed per produced ton of LNG) under the variation of the MR cooling reference temperature as well the feed gas pressure. 


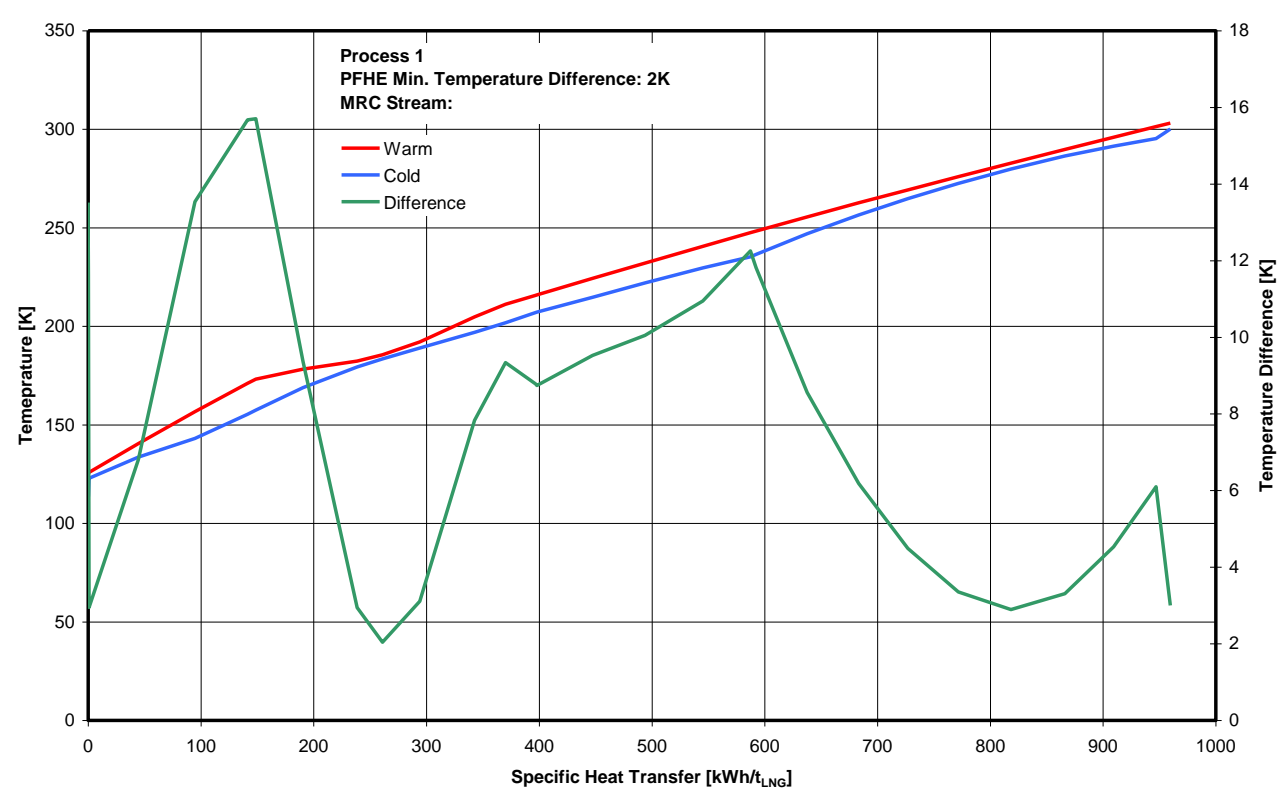

Fig. $10(\mathrm{Q} / \mathrm{T})$ diagram of PFHE in Process 1

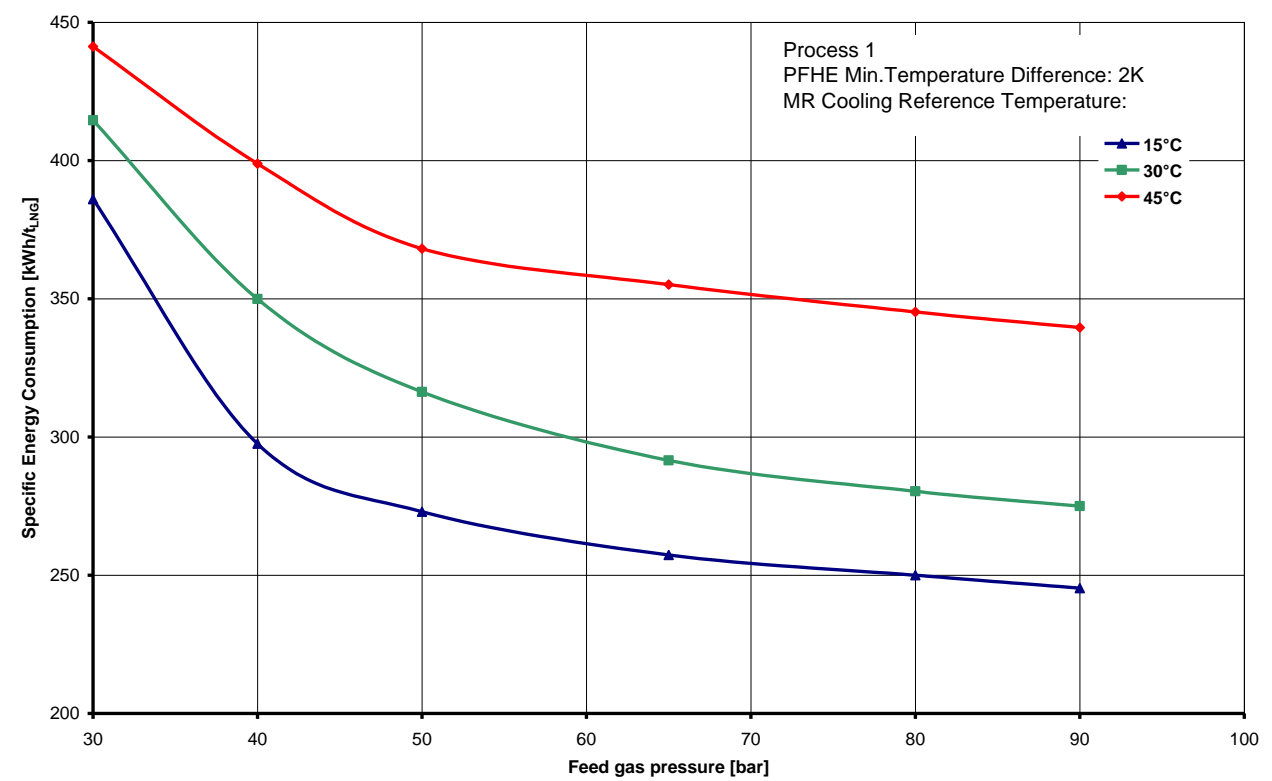

Fig. 11 Specific energy consumption behaviour in Process 1 for a minimal temperature difference of $2 \mathrm{~K}$ and MR cooling reference temperature of 15,30 and $45^{\circ} \mathrm{C}$

Figure 10 shows $(\mathrm{Q} / \mathrm{T})$ diagram of the cold and warm streams of PFHE (left abscissa) as well as the temperature difference (right abscissa) as a function of specific heat transfer within the PFHE for process 1 . As both warm and cold streams of PFHE lay close to each other without intersection; it can be indicated that the work done by MRC compressor is minimum. Here the maximal temperature difference of about $16 \mathrm{~K}$ is found on the warm part of PFHE, providing a phase change in MR, while a temperature difference of about $6 \mathrm{~K}$ is obtained on the cold part of the PFHE referring to the exergy losses on the cold part of the process. This adaptability in (Q/T) diagram is, in general, taken as an indication to the effectiveness of the MRC process.

As Figure 11 shows the specific energy consumption as a function of MR cooling reference temperature and feed gas pressure. In general, the MRC process is more effective (less specific energy consumption) when feed gas is operated under high pressures and lower MR cooling reference temperatures (low to moderate climate conditions), since lower cooling duty on MRC Compressor is 
required. By optimized process conditions achieving a pinch temperature (minimum temperature difference between cold and warm streams) for PFHE of $2 \mathrm{~K}$, the specific energy consumption for this process 1 is reading the value of $285 \mathrm{kWh} / \mathrm{tLNG}$ at $65 \mathrm{bar}$ feed gas pressure and $\mathrm{MR}$ cooling reference temperature of $30^{\circ} \mathrm{C}$, which is within the range of conventional single MRC process (typically 250 $350 \mathrm{kWh} / \mathrm{tLNG}$ (Jacobson (2009), Devold (2013) and Long et al. (2016)).

Figure 12 shows $(\mathrm{Q} / \mathrm{T})$ diagram of the cold and warm streams of PFHE (left abscissa) as well the temperature difference (right abscissa) as a function of specific heat transfer within the PFHE for process 2. As expected the inclusion of MP separator enhances the pre-cooling duty of PFHE. An improvement on total energy consumption is achieved for process 2 with respect to process 1 , enhancement of pre-cooling duty means a significant reduction on the isentropic work done by 1st MRC stage compressor. The maximal temperature difference is reduced to $13 \mathrm{~K}$, obtained at the warm part of PFHE, that is synchronized with a temperature difference of $18 \mathrm{~K}$, this is due to the phase change in the light and heavy MR streams in PFHE. On the other hand, the cold and warm streams are closer, which is in turn an indication for the further improvement of the effectiveness of process 2.

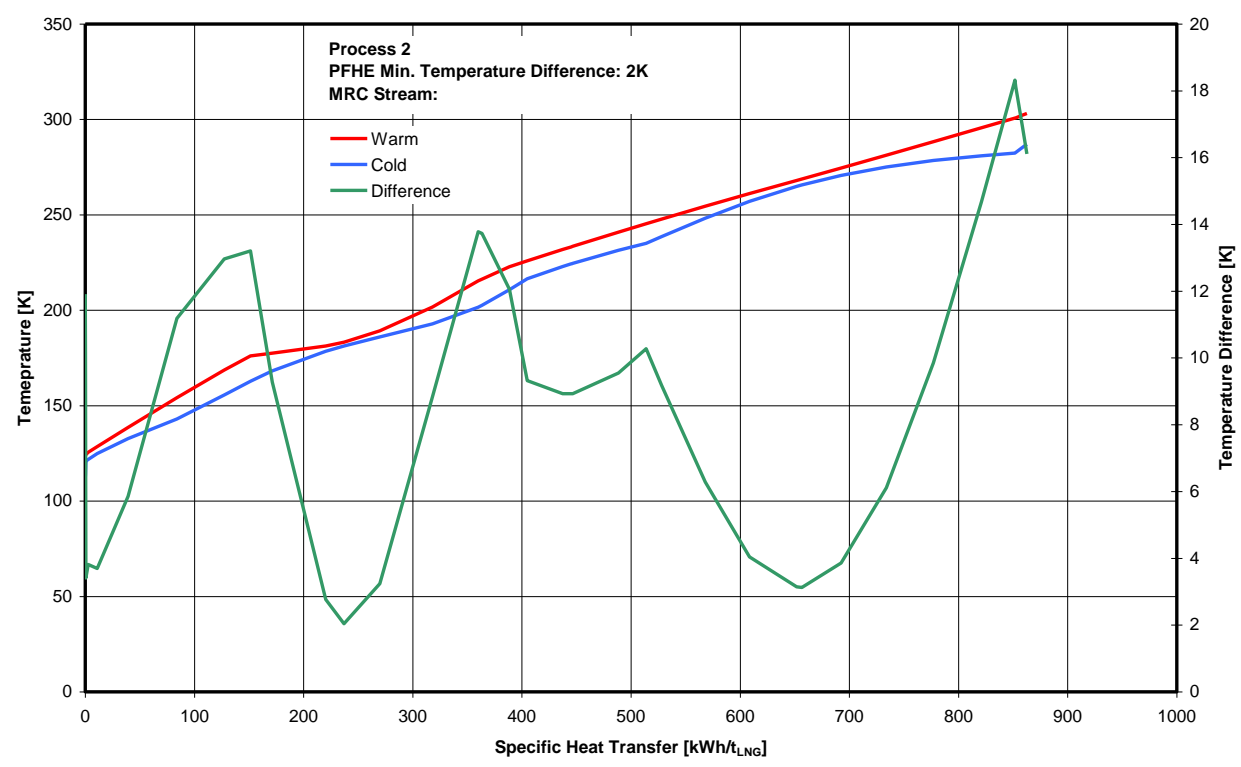

Fig. $12(\mathrm{Q} / \mathrm{T})$ diagram of PFHE in Process 2

Figure 13 shows the specific energy consumption as a function of MR cooling reference temperature and feed gas pressure. In comparison to Figure 11 lower specific energy consumption is obtained with respect to that of process 1 by a factor of $3 \%$.

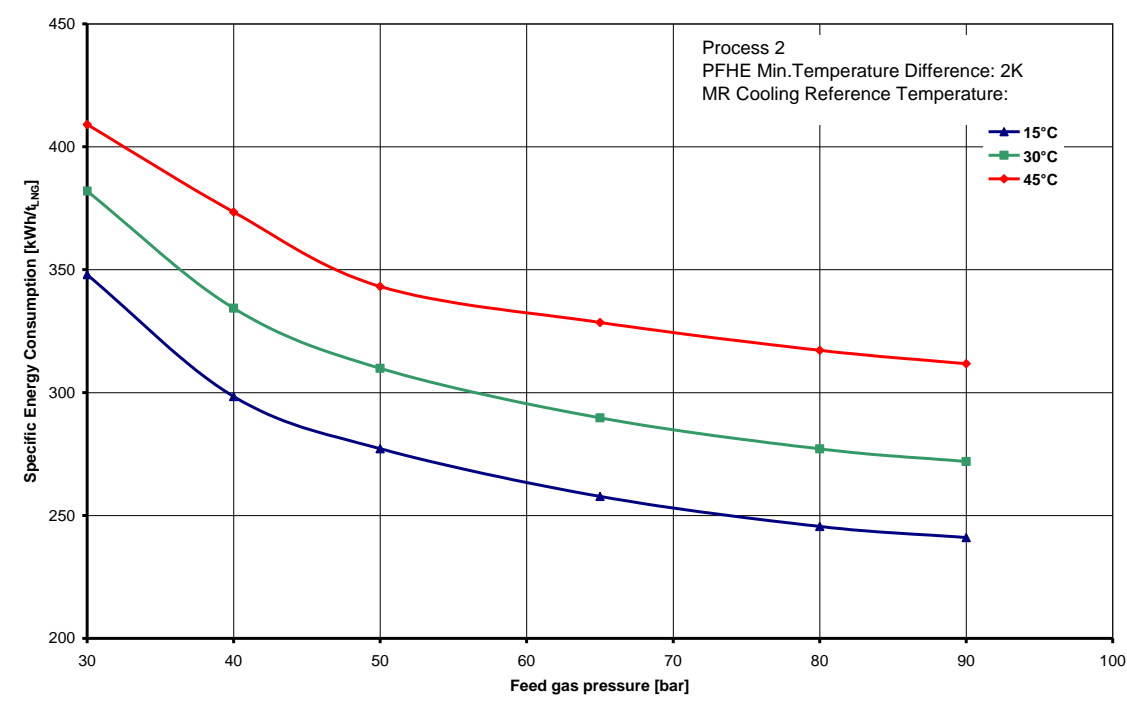

Fig. 13 Specific energy consumption behaviour in Process 2 for a minimal temperature difference of $2 \mathrm{~K}$ and $\mathrm{MR}$ cooling reference temperature of 15 , 30 , and $45^{\circ} \mathrm{C}$ 
Figure 14 shows $(\mathrm{Q} / \mathrm{T})$ diagram of the cold and warm streams of PFHE (left abscissa) as well as the temperature difference (right abscissa) as a function of specific heat transfer within the PFHE for process 3 . The maximal temperature difference is reduced to $12 \mathrm{~K}$ on the warm part of PFHE in comparison to that of process 1, a temperature difference of about $14 \mathrm{~K}$ obtained on the cold part of PFHE.

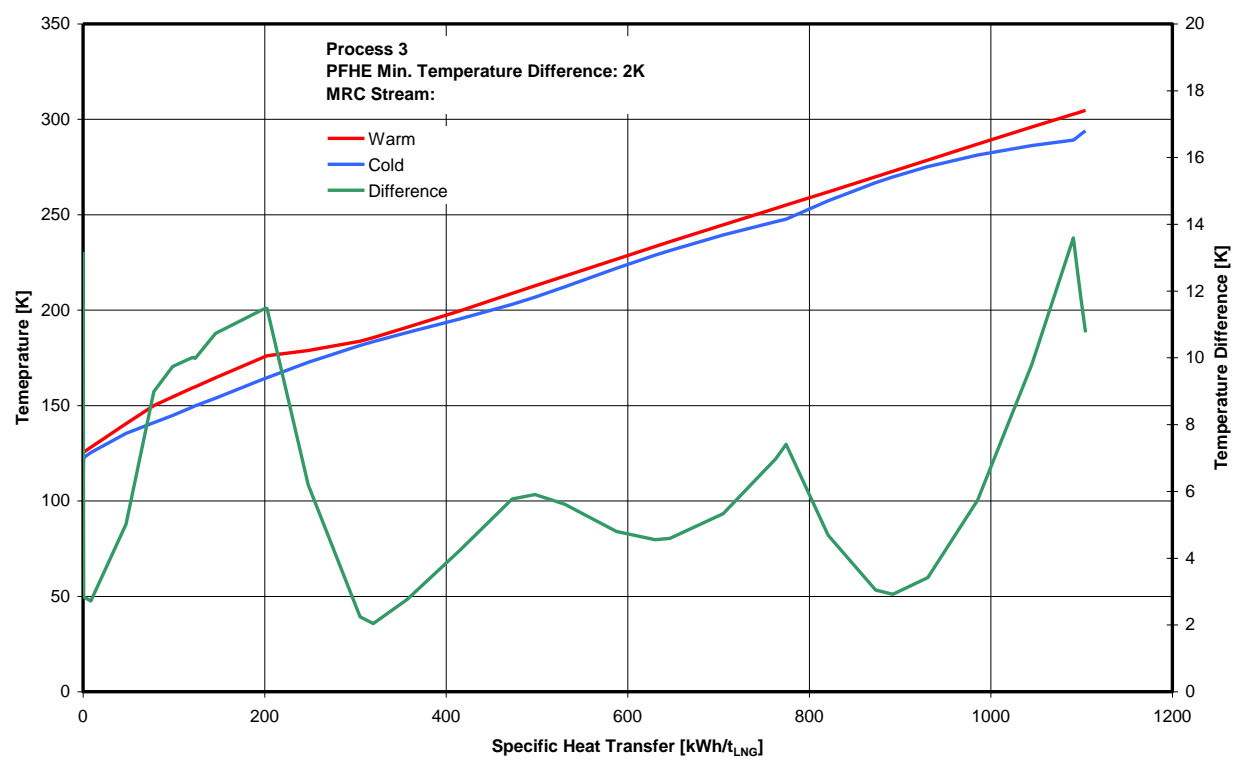

Fig. $14(\mathrm{Q} / \mathrm{T})$ diagram of PFHE in Process 3

Similar findings in Figure 15 are obtained compared to those of above Figures $11 \& 13$.

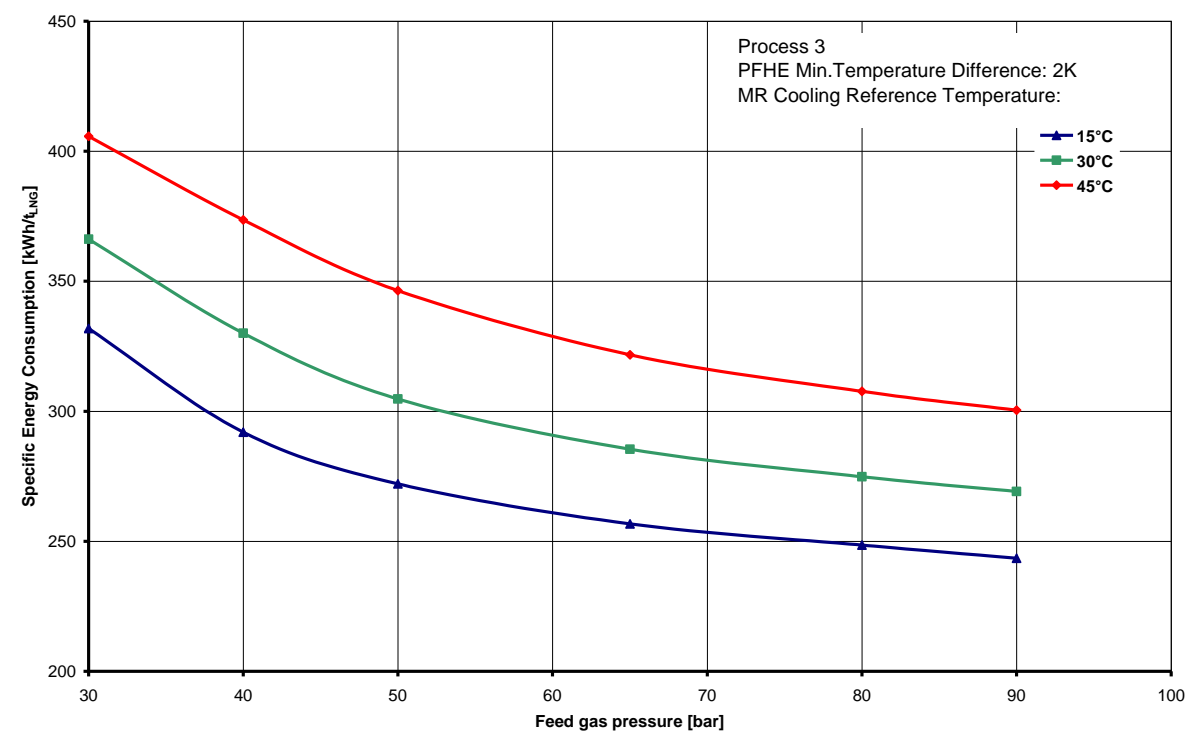

Fig. 15 Specific energy consumption behaviour in Process 3 for a minimal temperature difference of $2 \mathrm{~K}$ and MR cooling reference temperature of 15,30 and $45^{\circ} \mathrm{C}$ 


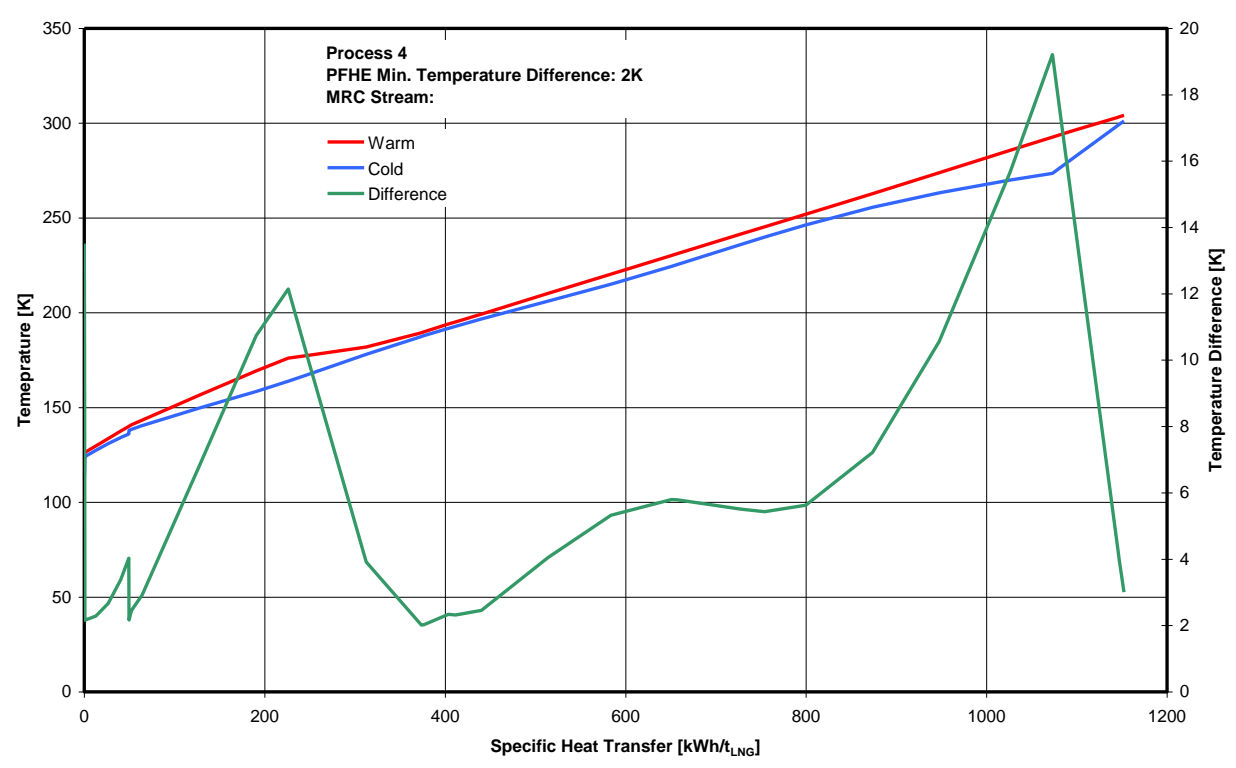

Fig. $16(\mathrm{Q} / \mathrm{T})$ diagram of PFHE in Process 4

Figure 16 presents $(\mathrm{Q} / \mathrm{T})$ diagram of the cold and warm streams of PFHE (left abscissa) as well as the temperature difference (right abscissa) as a function of specific heat transfer within the PFHE for process 4 . A reduction of about $7 \%$ in total specific heat transfer. Here the effect of the further improvements (MRC pump and mixing the cold and warm parts of PFHE) on MRC process performance highlights that a maximal temperature difference of about $12 \mathrm{~K}$ on the warm part of PFHE and 18K on the cold part of PFHE are obtained. This process reads a further reduction in the specific energy consumption of about $12 \%$ in comparison to that of process 1 . Figure 17 presents that the findings are in good agreement with previous relevant schemes. Energy consumption in comparison to that of process 1 at 65 bar inlet feed pressure and MR cooling reference temperature of $30^{\circ} \mathrm{C}$. It is observed that the behaviour of temperature difference in the liquefaction region of PFHE has two jumps, due to enhancement in the condensation curve for NG. This is achieved because of the MRC pump.

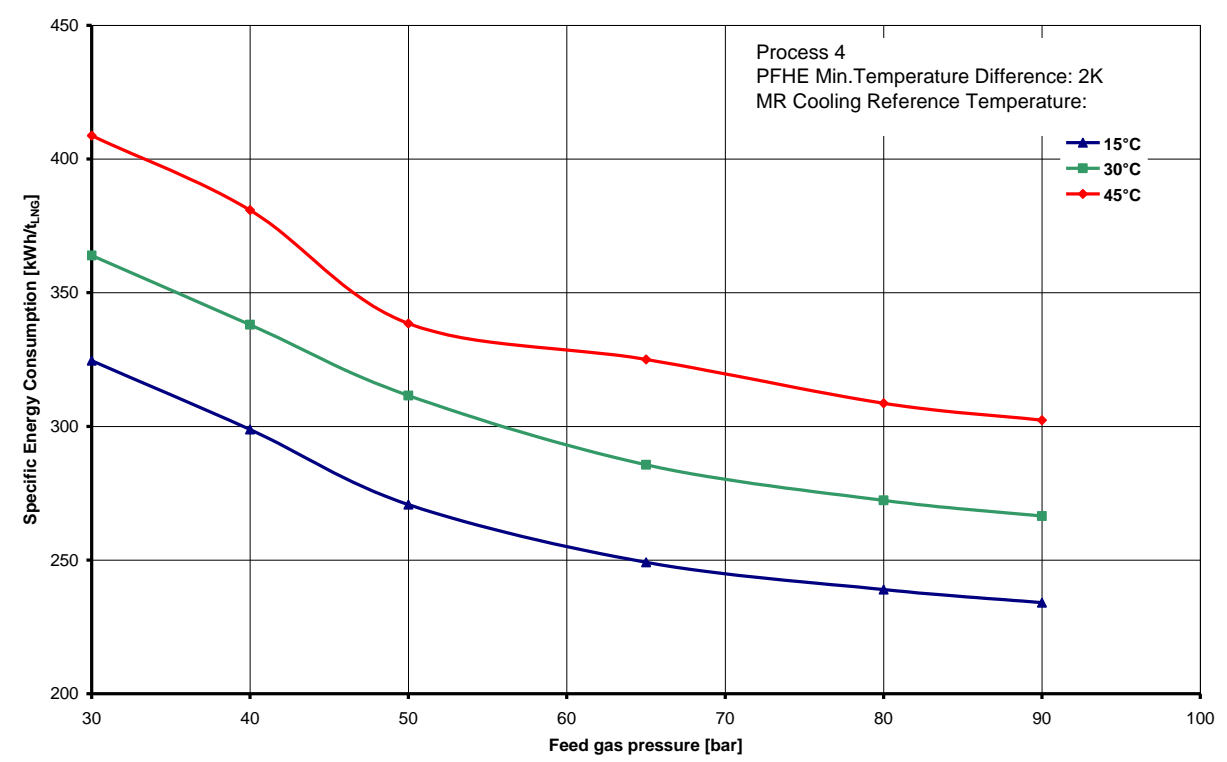

Fig. 17 Specific energy consumption behavior in Process 4 for a minimal temperature difference of $2 \mathrm{~K}$ and MR cooling reference temperature of 15,30 and $45^{\circ} \mathrm{C}$ 


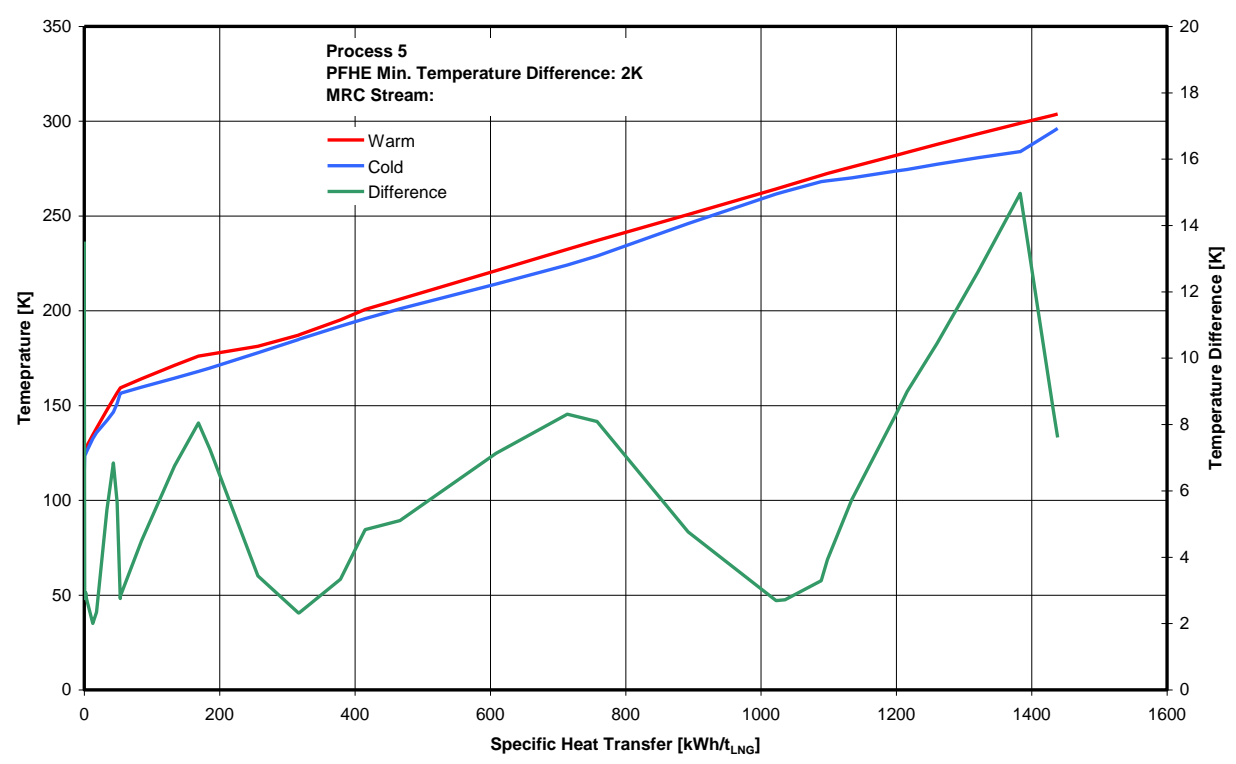

Fig. $18(\mathrm{Q} / \mathrm{T})$ diagram of PFHE in Process 5

Figure 18 presents $(\mathrm{Q} / \mathrm{T})$ diagram of the cold and warm streams of PFHE (left abscissa) as well as the temperature difference (right abscissa) as a function of specific heat transfer within the PFHE for process 5. The relevant improvements include MRC pump, mixing of cold and warm streams as well MR cold separator. These improvements indicate significant enhancements on pre-cooling and liquefaction duties compared to those obtained in process 4 , further enhancement is gained for sub-cooling duty of PFHE because of MR cold separator. This finding is proven in the behavior of temperature difference curve with respect to that of process 4 , where a maximal temperature difference of about $8 \mathrm{~K}$ is obtained on the warm part of PFHE, $8 \mathrm{~K}$ around the mixing point and $14 \mathrm{~K}$ at cold part of PFHE. Also, findings in Figure 19 are in good agreement with above mentioned facts. The MRC process is more effective (less specific energy consumption) with a factor $14 \%$ with respect to that of process 1 .

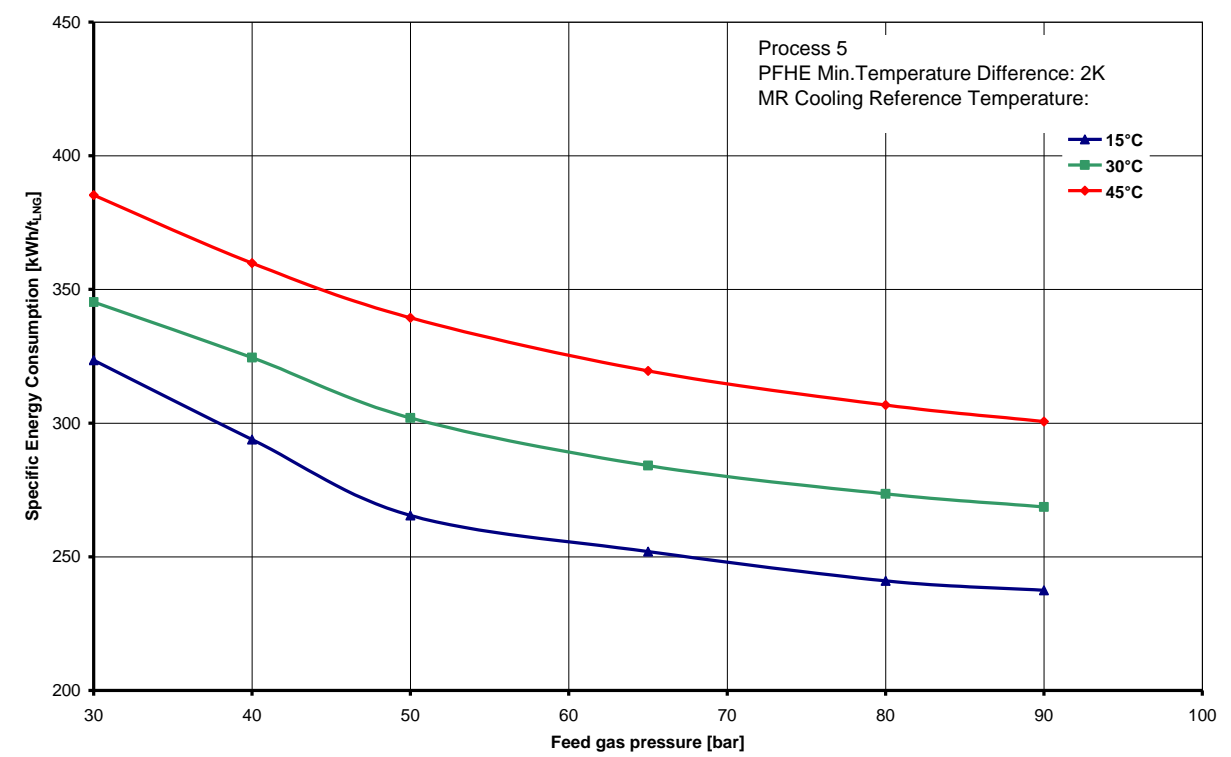

Fig. 19 Specific energy consumption behaviour in Process 5 for a minimal temperature difference of $2 \mathrm{~K}$ and MR cooling reference temperature of 15,30 and $45^{\circ} \mathrm{C}$ 


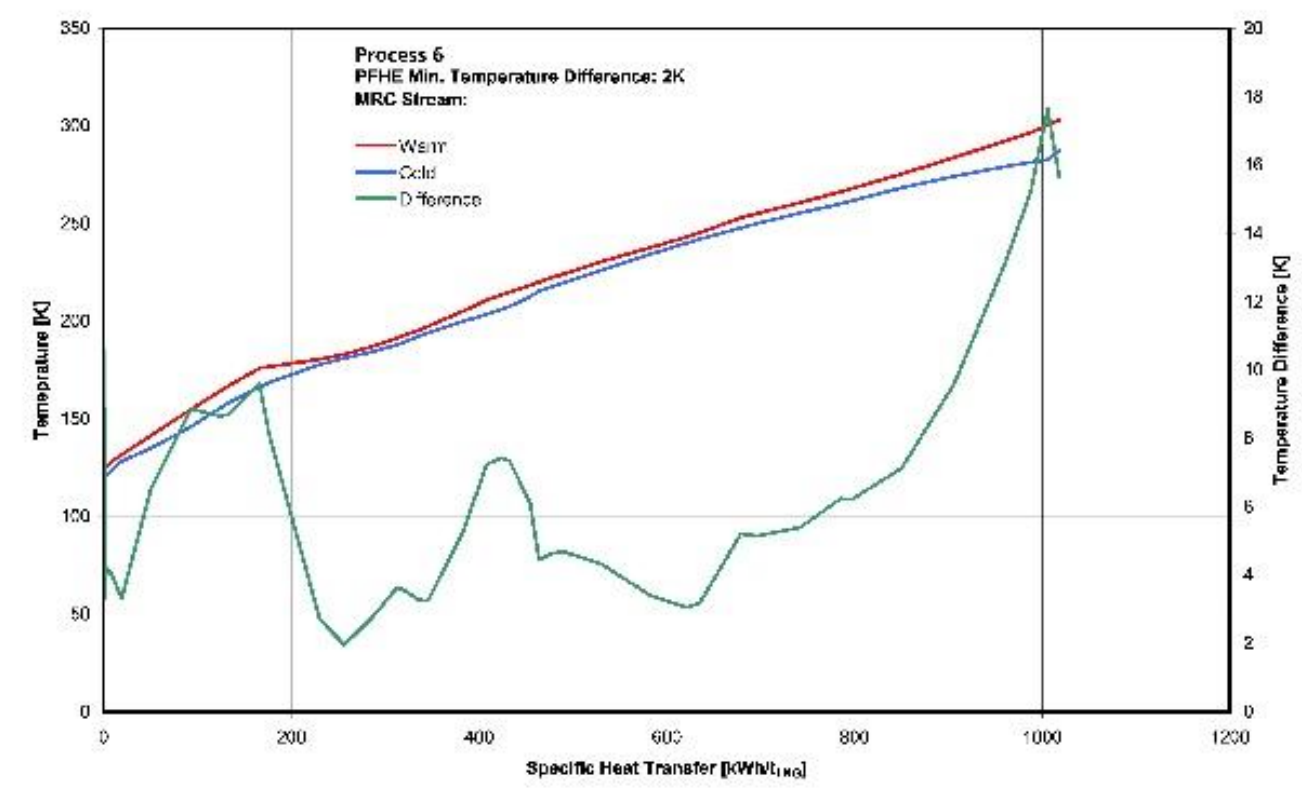

Fig. $20(\mathrm{Q} / \mathrm{T})$ diagram of PFHE in Process 6

Figure 20 presents $(\mathrm{Q} / \mathrm{T})$ diagram of the cold and warm streams of PFHE (left abscissa) as well as the temperature difference (right abscissa) as a function of specific heat transfer within the PFHE for process 6 . Obtaining a maximal temperature difference of about $8 \mathrm{~K}$ on the warm end and $18 \mathrm{~K}$ on the cold end of PFHE respectively, due to the warming of two phase stream fed from the position of mixing gas and liquid MR from HP separator prior to be routed to PFHE and finally expanded in JT valve to provide the essential subcooling duty of PFHE. Both warm and cold streams in PFHE are closely, which implies, in turn, an indication of relatively higher process effectiveness.

Figure 21 shows the simulation outputs of specific energy consumption as a function of a MR cooling reference cooling temperature and feed gas pressure. Effectiveness of process 6 reads an enhancement factor of about $16 \%$ of total energy consumption compared to process 1 .

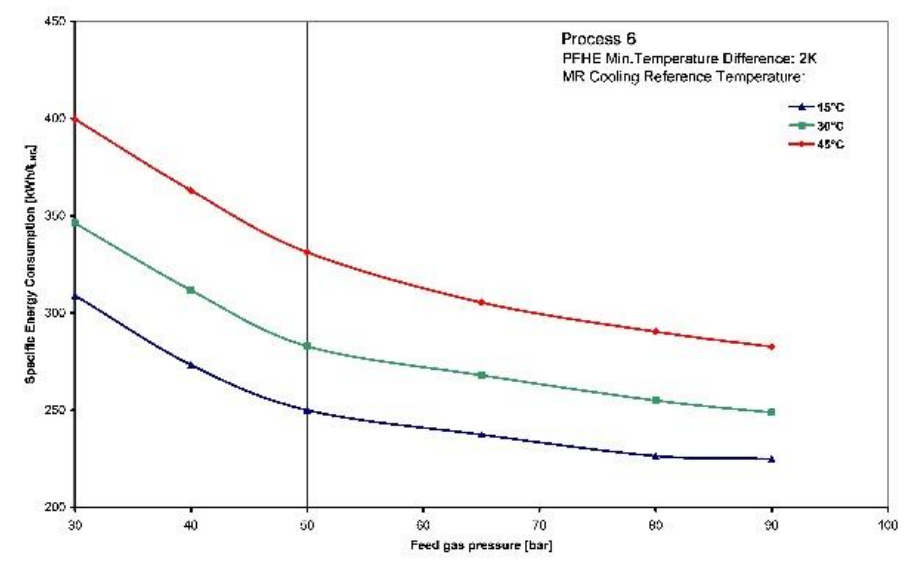

Fig. 21 Specific energy consumption's behaviour in Process 6 for a minimal temperature difference of 2K and MR cooling reference temperature of 15, 30 and $45^{\circ} \mathrm{C}$

The results of process 7 regarding $(\mathrm{Q} / \mathrm{T})$ diagram of the cold and warm streams of PFHE (left abscissa) as well as the temperature difference (right abscissa) as a function of specific heat transfer within the PFHE is presented in Figure 22. Obtaining a maximal temperature difference of about $12 \mathrm{~K}$ on the warm end and $17 \mathrm{~K}$ on cold end of PFHE, due to the cooling of MP MR with expanding HP MR prior to be routed to PFHE, the other process configurations are identical to those of process 5.

Achievements on specific energy consumption of process 7 is shown in Figure 23. This process records a further improvement in the energy consumption of a factor of about $14 \%$, which is near to that of process 5 under identical MRC configurations. 


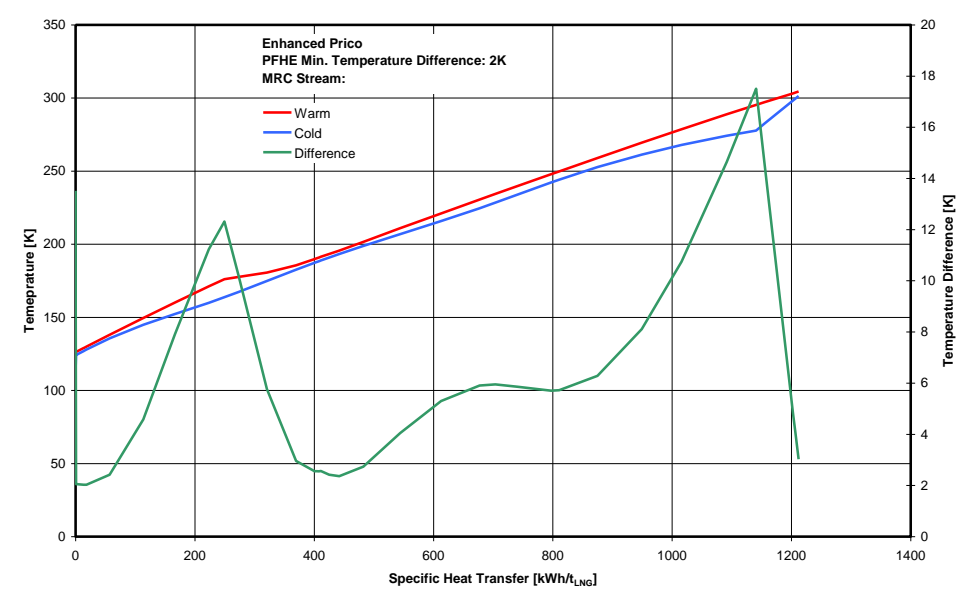

Fig. $22(\mathrm{Q} / \mathrm{T})$ diagram of PFHE in Process 7

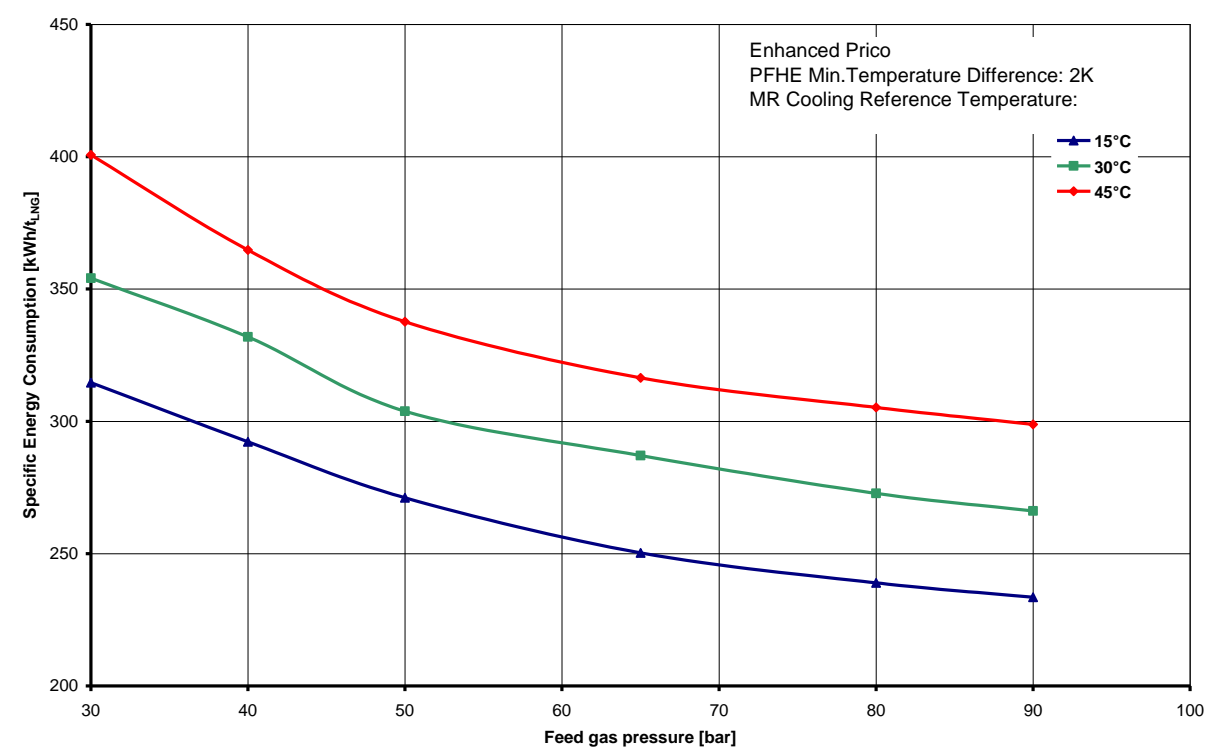

Fig. 23 Specific energy consumption behaviour in Process 7 for a minimal temperature difference of $2 \mathrm{~K}$ and MR cooling reference temperature of 15,30 and $45^{\circ} \mathrm{C}$

Table 4 indicates the comparison design criteria for the investigated process concepts, run for MRC process boundary conditions listed in Table 3. All investigated concepts are performed under cryogenic temperature ranges, the operating conditions for considering the relevant topology are classified either simple or sophisticated according to the account of Joule Thomson valves implemented in the concept. Process 6 involves 2 Joule Thomson valves, so is considered as simple concept. Because it is run under basically the easiest controlled operating conditions, hence then has the lowest process complexity as well the relatively simplest automation scenario.

Plant availability is justified by the presence of rotating equipments (cryogenic pumps) in the process as fair. While the absence of cryogenic pumps indicates a high plant availability, in this context processes 1, 2 and 7 prevail. The design criteria including OPEX and CAPEX indicate that processes $2 \& 7$ are comparable with respect to process 6 . From the above findings, the improvements, performed for all above processes, are achieving the best readings for process 6 . These findings will be further examined under different feed gas pressures and MR cooling reference temperatures, moreover will be compared with process 7, where enormous effects of process topology variation cause the process to be significantly effective. Designing of PFHE with minimal temperature difference less than $2 \mathrm{~K}$ is not preferable due to economic reasons, hence then a PFHE with a relatively large heat transfer area is required. By comparing between the MRC processes 1 to 5 , generally process 2 is recording the best results for the investigated range of minimal temperature difference of $2 \mathrm{~K}$. So that process 2 will also be considered for further investigations. 
Table 4 Comparison criteria for LNG processes (Based on MRC process conditions listed in Table 3)

\begin{tabular}{|c|c|c|c|c|c|c|c|}
\hline Process & 1 & 2 & 3 & 4 & 5 & 6 & 7 \\
\hline $\begin{array}{l}\text { Expected energy } \\
\text { consumption [\%] }\end{array}$ & 115 & 110 & 115 & 115 & 115 & 100 & 105 \\
\hline $\begin{array}{l}\text { Expected total } \\
\text { installation costs } \\
{[\%]}\end{array}$ & 90 & 90 & 100 & 110 & 120 & 100 & 150 \\
\hline Equipment count & $\begin{array}{l}1 \text { Comp. } \\
1 \text { Vessel } \\
3 \text { HEX, } \\
3 \text { Valve }\end{array}$ & $\begin{array}{l}1 \text { Comp. } \\
2 \text { Vessel } \\
3 \text { HEX } \\
3 \text { Valve }\end{array}$ & $\begin{array}{l}1 \text { Comp. } \\
2 \text { Vessel } \\
1 \text { Pump } \\
3 \text { HEX } \\
3 \text { valve }\end{array}$ & $\begin{array}{l}1 \text { Comp. } \\
2 \text { Vessel } \\
1 \text { Pump } \\
4 \text { HEX } \\
3 \text { valve }\end{array}$ & $\begin{array}{l}1 \text { Comp. } \\
3 \text { Vessel } \\
1 \text { Pump } \\
4 \text { HEX } \\
4 \text { Valve }\end{array}$ & $\begin{array}{l}1 \text { Comp. } \\
2 \text { Vessel } \\
2 \text { Pump } \\
3 \text { HEX } \\
2 \text { Valve }\end{array}$ & $\begin{array}{l}1 \text { Comp. } \\
3 \text { Vessel } \\
5 \text { HEX } \\
6 \text { Valve }\end{array}$ \\
\hline $\begin{array}{l}\text { Plant availability } \\
\text { [\%] }\end{array}$ & High & High & Fair & Fair & Fair & Fair & High \\
\hline $\begin{array}{l}\text { Operating } \\
\text { conditions }\end{array}$ & $\begin{array}{l}\text { Sophisticated } \\
\text { cryogenic } \\
\text { temperature }\end{array}$ & $\begin{array}{l}\text { Sophisticated } \\
\text { cryogenic } \\
\text { temperature }\end{array}$ & $\begin{array}{l}\text { Sophisticated } \\
\text { cryogenic } \\
\text { temperature }\end{array}$ & $\begin{array}{l}\text { Sophisticated } \\
\text { cryogenic } \\
\text { temperature }\end{array}$ & $\begin{array}{l}\text { Sophisticated } \\
\text { cryogenic } \\
\text { temperature }\end{array}$ & $\begin{array}{l}\text { Simple } \\
\text { cryogenic } \\
\text { temperature }\end{array}$ & $\begin{array}{l}\text { Sophisticated } \\
\text { cryogenic } \\
\text { temperature }\end{array}$ \\
\hline
\end{tabular}

The Fig. 24-26 summarize the difference in specific total energy consumption as a function of the investigated range of feed gas pressures, for processes 2 (Foss (2005)) and 7 (Andress (1996)) with respect to process 6 (Stockman et al. (2002), Al Rabadi (2017)), considering similar conditions of PFHE minimum temperature of $2 \mathrm{~K}$ and various reference temperature refrigerant of 15,30 and $45{ }^{\circ} \mathrm{C}$, for simulating the diverse of metrological conditions for different LNG plants' locations around the world. The process calculations are done for PEHE minimal temperature difference with $2 \mathrm{~K}$. It is obvious that the process is showing a better performance with lower minimal temperature difference on PFHE, and higher inlet feed gas pressure. More over lower specific energy consumption is obtained with the low MR cooling reference temperature, then lower duty on the MRC compressor is required.

Process 2 and 7 are recording higher figures for difference in total energy consumption with respect to those of process 6 . As observed from Figure 24 the findings for process 2, is decreasing with gas feed pressure. The major influencing factor on the specific energy consumption in the refrigerant condensation process is the attainable enthalpy difference, hence the more refrigerant, condensed with using the cooling water, the more energy efficient is the condensation process. Considering the situation in process 7 , its reading of a relatively better performance due to inclusion of cold MR separator on the cold end of PFHE. The difference for process 7 reaches a maximum around the feed gas pressure of 50 bar due to thermodynamic equilibrium between liquid and gas phases of MR.

The findings in Figure 25 take a different trend that seems to be almost identical difference for each process starting from a feed gas pressure of 40 bar. Meaning that the process configurations, of $\mathrm{MR}$ cooling reference temperature refrigerant of $30{ }^{\circ} \mathrm{C}$, are recording almost the same level of specific energy consumption. Whereas in warm metrological regions the trend of difference in total energy consumption is increased for both processes 2 and 7, hence higher energy consumption figures are expected on the MRC compressors, refer also to Figure 26. 


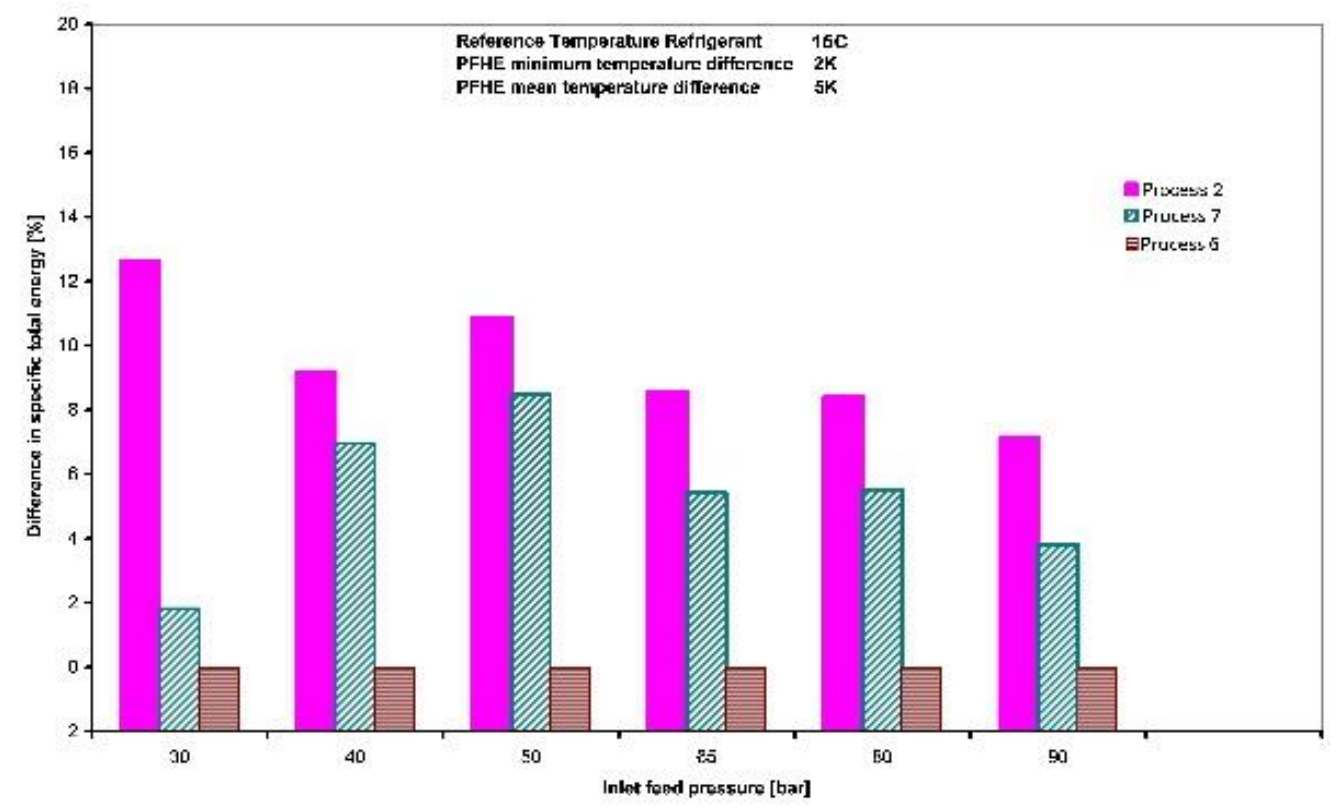

Fig. 24 Difference in total energy consumption for $15^{\circ} \mathrm{C}$ as MR cooling reference temperature

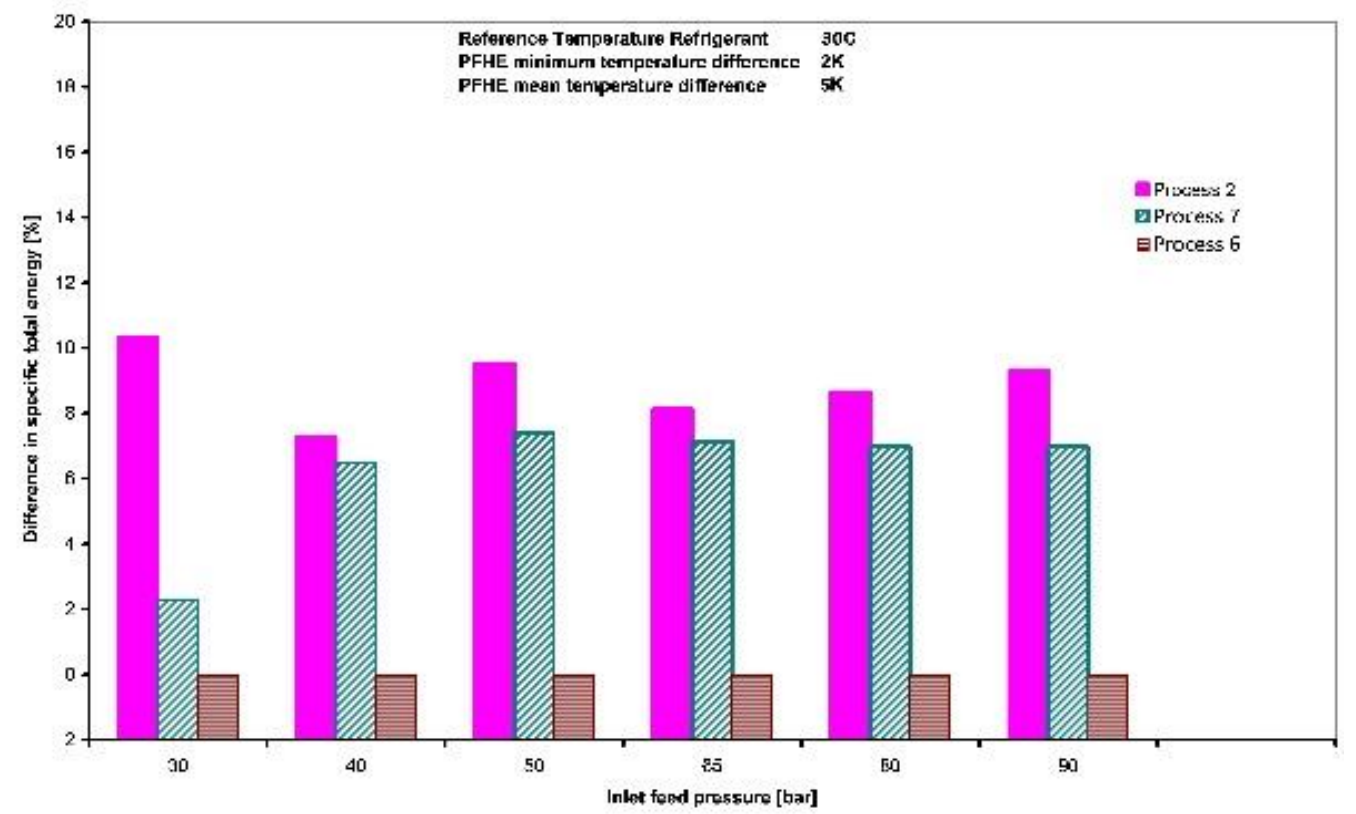

Fig. 25 Difference in total energy consumption for $30^{\circ} \mathrm{C}$ as MR cooling reference temperature 


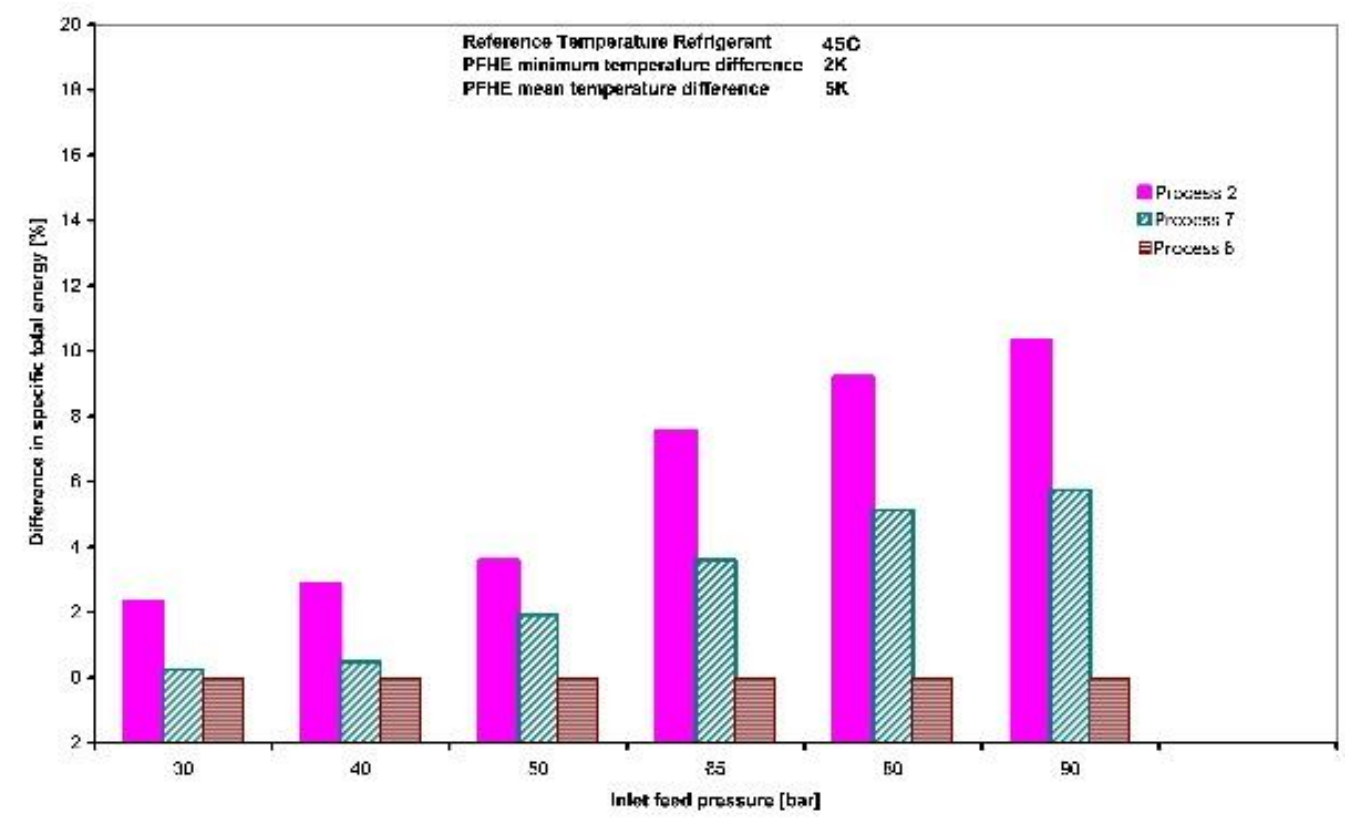

Fig. 26 Difference in total energy consumption for MR cooling $45^{\circ} \mathrm{C}$ as reference temperature

\section{Conclusions}

From the above findings, it can be concluded that the new improvements, proposed and compared with almost exclusively commercial trademarks processes in NG plant design, which mainly include the design of NG liquefaction and refrigeration cycle, are achieving considerable energy savings as potentially are reducing the capital and operating costs of the plants, through reducing its footprint. These improvements are compatible for power-efficient, off- \& onshore liquefaction plants, decreasing plant complexity scenarios from automation engineering point of view, as for ecological reasons. So can assembly simulations parameters, be concerning energy density and equipment design, have the major impact on cost, or the so called benefit ratio, this is defined as the ratio between the price of the product and the plant efficiency. These parameters are indication on the potential energy savings by means of integration the traditional liquefaction processes with the proposed improvements on the plant layout, as well with optimization of the process conditions of MRC. More investigations are required to account for a moderate scalability of the modeled process improvements with respect to large scale plants. Furthermore, considerations for plant design with other commercial types of cryogenic heat exchangers are meriting further theoretical and industry related investigations.

\section{Acknowledgments}

Grateful thanks for the support awarded by The Linde Group Firm, a special addressing to Mr. Rainer Sapper for the high-valued supervision in the execution of this research work. This work substantially overlaps research interests and corporation between the Linde Group and the academia.

\section{Nomenclature}

$\begin{array}{ll}\text { Acronym } & =\text { Description } \\ \mathrm{APCI} & =\text { Air Products \& Chemicals, Inc. } \\ \mathrm{BP} & =\text { British Pertoleum Corp. North America } \\ \mathrm{C} 3 \mathrm{MR} & =\text { Propane mixed refrigerant } \\ \mathrm{dT}_{\min } & =\text { Minimal Temperature difference } \\ \mathrm{dp}_{\text {Fuel }} & =\text { Pressure drop on Fuel gas stream } \\ \mathrm{dp} & =\text { Pressure drop on MRC steams } \\ \mathrm{DMR} & =\text { Dual mixed refrigerant } \\ \eta_{\text {isen }} & =\text { Isenstropic efficiency } \\ \mathrm{JT} & =\text { Joule-Thomson }\end{array}$


Q $\quad=$ Insolation heat loss

$\eta_{\text {isen }} \quad=$ Isentropic compressor efficiency

$\mathrm{T}_{\text {inlet }} \quad=$ Inlet temperature

$\mathrm{T}_{\text {outlet }} \quad$ =Outlet temperature

$\mathrm{p}_{\text {outlet }} \quad=$ Outlet Pressure

$\mathrm{P}_{\text {inlet }} \quad=$ Inlet pressure

CAPEX =Capital costs

$\mathrm{dp}_{\mathrm{MR}} \quad=$ Mixed refrigerant stream pressure drop

HP =High pressure

LNG $\quad$ =Liquefied natural gas

MP $\quad=$ Medium Pressure

MR =Mixed refrigerant

MTPA $\quad=$ Million tonne per annum

$\mathrm{NG} \quad=$ Natural gas

MFCP =Mixed fluid cascade process

MRC = Mixed refrigerant cycle

PFHE $\quad=$ Plate Fin Heat Exchanger

PRICO =Poly Refrigerant Integrated Cycle Operations

SMR $\quad=$ Single mixed refrigerant

\section{References}

Agrawal, M. R., "Dual mixed refrigerant cycle for gas liquefaction", Patent No.09/208,562 (1998).

Al Rabadi, S., "Improvements to configurations of natural gas liquefaction cycles", The 8th Jordan International Chemical Engineering Conference, Amman Jordan, 7 - 9 November (2017).

Andress, D. L., "The Phillips optimized cascade lng process a quarter century of improvement", The Permission of the Institute of Gas Technology (1996).

Cengel, Y. A. and M. A. Boles, "Thermodynamics an engineering approach". McGraw-Hill, New York (2002).

Coll, R., E. Carbon, and J. Delgado, "Technology evaluation Methodology for Stranded Gas Monetization Options", 19 $9^{\text {th }}$ WPC, 2008 29th June - 3rd July, Madrid, Spain.

Devold, H., "Oil and gas production handbook An introduction to oil and gas production, transport, refining and petrochemical industry", Edition 3.0 Oslo, ISBN 978-82-997886-3-2 (2013).

Fischer-Calderon, E., "Self-refrigerated LNG process", US Patent 6564578 B1(2003).

Foss, M, "Global Natural Gas Issues and Challenges", The Energy Journal, 26, 111-128 (2005).

Jacobson, M. Z., "Review of solutions to global warming, air pollution, and energy security", Energy Environ. Sci. 2, 148-173 (2009).

Kroener, A., "An engineering Company's approach to filling "CAPE gaps" in process simulation", Computer Aided Chemical Engineering, 21, 781-786, (2006).

Laursen, J. K. and A. N. Karavanov, "Processes for sulfur recovery, regeneration of spent acid, and reduction of NOx emissions", Chem. Petrol. Eng. 42, 229234 (2006).

Long, N. V. D., L.Q. Minh, T.N. Pham, A. Bahadori, and Lee M., "Novel retrofit designs using a modified coordinate descent methodology for improving energy efficiency of natural gas liquid fractionation process", Jour. Nat. Gas Sci. Eng., 33, 458-468 (2016).

Metz, B. and Davidson O., "IPCC special report on carbon dioxide capture and storage. Working Group III. Intergovernmental Panel on Climate Change", Cambridge University Press, Cambridge (2005).

Pereira, C. and D. Lequisiga "Technical Evaluation of C3-MR and Cascade Cycle on Natural Gas Liquefaction Process", Inter. Jour. of Chem. Eng. and Appl., $\mathbf{5}, 451-456(2014)$.

Perez, S. and R. Dietz "Opportunities of monetising natural gas reserves using small to medium scale LNG technologies". REPSOL (2009).

Smith, J. M., M. Van Ness and M. Abbott "Introduction to Chemical Engineering Thermodynamics", $5^{\text {th }}$ edition, Mc Graw Hill International Editions, (1996).

Stockmann, R., M. Bolt, M. Steinbauer, C. Pfeiffer, P. Paurola, W. Forg, A. O. Fredheim and Sorensen O., "Process for liquefying a hydrocarbon-rich stream", US Patent 6334334 B1 (2002).

Wonsub, L., C. Kwangho and I Moon "Current Status and Perspectives of Liquefied Natural Gas (LNG) Plant Design", Ind. Eng. Chem. Res., 52 , 3065-3088 (2013). 